Federal Reserve Bank of Dallas

Globalization and Monetary Policy Institute

Working Paper No. 38

http://www.dallasfed.org/assets/documents/institute/wpapers/2009/0038.pdf

\title{
A Model of International Cities: Implications for Real Exchange Rates*
}

\author{
Mario J. Crucini \\ Vanderbilt University \\ Hakan Yilmazkuday \\ Temple University
}

September 2009

\begin{abstract}
We develop a model of cities each inhabited by two agents, one specializing in manufacturing, the other in retail distribution. The distribution sector represents the physical transformation of all internationally traded goods from the factory gate to the final consumer. Using a panel of micro-prices at the city level, we decompose the cross-sectional variance of long-run LOP deviations into the fraction due to distribution costs, trade costs and a residual. For the median good, trade costs account for 50 percent of the variance, distribution costs account for 10 percent with 40 percent of the variance unexplained. Since the sample of items in the data are heavily skewed toward traded goods, we also decompose the variance based on the median good on an expenditure-weighted basis. Now the tables turn, with distribution costs accounting for 43 percent, trade costs 36 percent and 21 percent of the variance unexplained.
\end{abstract}

JEL codes: E30, F31, D41

\footnotetext{
* Mario Crucini, Department of Economics, Vanderbilt University, VU Station B \#351819, 2301 Vanderbilt Place, Nashville, TN 37235-1819. mario.j.crucini@vanderbilt.edu. Hakan Yilmazkuday. 615322-7357. Department of Economics, Temple University, Philadelphia, PA 19122. 215-204-1762. hakan.yilmazkuday@temple.edu. We especially thank Mary Amiti, Eric Bond, Paolo Pesenti and Robert Vigfusson for valuable comments and criticisms. We are grateful to seminar participants at the California State University, Long Beach, Federal Reserve Banks of Dallas and New York, Utah State University, Temple University, University of Tennessee at Knoxville and Vanderbilt University; conference participants at the 2008 Midwest International Economics Meeting at The Ohio State University, the 2008 Midwest Annual Meeting participants in Chicago, IL, the Wegman's Conference at the University of Rochester, and the Murray S. Johnson Memorial Conference, The University of Texas at Austin. The authors gratefully acknowledge the financial support of the National Science Foundation (SES-0136979, SES-0524868). The views in this paper are those of the authors and do not necessarily reflect the views of the Federal Reserve Bank of Dallas or the Federal Reserve System.
} 


\section{Introduction}

We build a model of international cities with each city inhabited by two representative agents, a manufacturer and a retailer. The manufacturer produces a single homogeneous good using labor as the only input. The manufactured good is transported to all other cities with deviations in the prices of these traded goods across cities arising from transportation costs from the factory gate to the receiving dock at the retail establishment. The retailer allocates some fraction of her time and a local fixed factor to the provision of final goods (as well as pure services) in her city of residence. The value added by the retailer constitutes the distribution costs in our model. The economic role of the retailer is broader than suggested by the label: a good-specific distribution share parameter allows us to capture a spectrum of final consumption goods ranging from pure local services to internet purchases.

The equilibrium of the model pins down the manufacturing wage premium within each city and relative wages across cities. The manufacturing wage premium (relative to retailing) is declining in the consumption-expenditure-weighted distribution share. The relative wage across cities, in both sectors, is pinned down by the specialization assumption. The highest wage city is the city that produces the good with the highest product of two key parameters: the consumption expenditure share and traded input share (which is one minus the distribution share).

Local wages, land prices and trade costs enter a cost function, specific to the city and good, which determines the retail market price. These cost functions form the basis for LOP variance decompositions (variance of prices across cities) into distribution margins, trade cost margins and residuals, good-by-good. The distribution margins are further parsed into the influences of service sector wages and retail infrastructure costs across cities. The Economist Intelligence Unit (EIU) retail price data along with supplementary sources for wages and rental prices at the city level are used in the empirical work. Since the model assumes perfect competition and abstracts from official barriers to trade, the residual in the regression equation is expected to include markups, official barriers to trade and measurement error.

We have two sets of results, one for the sources of LOP deviations for the median good, the other for the differences in the sources of LOP deviations across goods in the cross- 
section. For the median good in the EIU sample, trade costs account for about 50 percent of LOP deviations, the distribution margin accounts for about 10 percent and the remaining 40 percent is unaccounted for. Because the median good in the EIU has a distribution share of only 0.2 , well below the aggregate distribution share of about 0.5 in the U.S. National Income and Product Accounts, we also report variance decomposition results centered on this parameter value. Now the tables turn, with distribution costs accounting for 43 percent, trade costs 36 percent and 21 percent of the variance (in LOP deviations) left unexplained.

The absolute level of cross-sectional retail price variance rises when a border is crossed as one would expect or when comparisons are made between cities with vastly different wealth levels. However, the relative importance of trade costs and distribution costs in accounting for this variance is fairly stable across sets of locations that include high and low income countries and when comparing within country and cross-border city pairs. One exception is the division of the variance accounted for by the distribution sector into the cost of labor and capital. Variance of the distribution costs across low income countries is dominated by differences in the rental component, with wages playing a smaller role. For other countries, the division of the distribution costs into the contribution of wages and rental prices is closer to equality.

Turning to differences in geographic price dispersion across goods, we find substantial heterogeneity. In the international data, the distribution margin accounts for 50 percent of cross-sectional variance in LOP deviations for the good with the highest distribution share and this fraction falls to a mere 10 percent as we move to the good with the lowest distribution share. Retail infrastructure accounts for more than 30 percent of the crosssectional variance in LOP deviations across Canada and the United States for the good with the highest infrastructure intensity, while accounting for virtually none of the variance for the good with the lowest infrastructure intensity.

Our theoretical model is closest to Giri (2009) who adds a good-specific distribution cost to the Eaton-Kortum (2002) model. In Giri's model distribution services are in fixed proportion to the physical units of the base good as in Burstein, Neves and Rebelo (2003) (BNR) with efficiencies drawn from a distribution with a country-specific mean and common world-wide variance. In contrast, we assume that the technological parameter for distribution 
inputs is good-specific while the productivity of the distribution sector is city-specific. Given that this margin is measurable in the NIPA, we view this as a more tractable way to model the distribution sector than the random efficiency approach. Our model shares with Alvarez and Lucas (2007), Atkeson and Burstein (2007), Eaton and Kortum (2002), and Naknoi (2008) an interest in the role of traditional trade costs. However, to the extent these papers incorporate a distribution sector, it is a common wedge across all goods in the retail basket, which assumes away any cross-sectional variance in price deviations due to the distribution margin. We find this heterogeneity to be essential for improving our understanding of LOP deviations.

Our empirical work builds upon Crucini, Telmer and Zachariadis (2005; henceforth CTZ) who study microeconomic price dispersion in retail markets across European capital cities using a series of rich cross-sections of Eurostat data at five year intervals from 1975 to 1990. They regress good-by-good price dispersion on an estimate of the share of non-traded inputs into retail production and a trade share, both of which they view as proxies for trade costs, broadly defined. They find price dispersion to be rising in the non-traded input share and declining in the trade share. The signs of their coefficients are consistent with our model and our empirical findings. The key advantages of our approach include: a substantially larger sample of locations; the use of a structural economic model; and the use of direct measures of local wages and land prices to measure the role of the distribution sector.

Also related are recent studies that focus on the variance of the prices of traded goods from a single source to destinations stratified by relative wages or income. Alessandria (2004) and Alessandria and Kaboski (2007) argue that high wage countries are charged a higher markup at the dock because search costs are born at the destination and are positively related to wages. Choi, Hummels and Qiang (2009) argue that it is infeasible to measure the prices of identical goods and attribute the positive correlation between markups and income to the fact that higher income individuals are willing to pay a premium for quality. These are plausible and interesting sources of variation in markups, which, due to data constraints, we are forced to relegate to our residual term. 


\section{The Model}

Each city, indexed by $j$, is inhabited by two representative agents. As is usual in representative agent frameworks, these two agents should be viewed as stand-ins for a large number of atomistic agents of each type, since we will be assuming perfect competition in all factor and final goods markets throughout. In each city, one agent specializes in the production of a single traded good, indexed by $i$, while the other specializes in retail trade and production of non-traded services. Production in the manufacturing sector is proportional to labor input, the factor of proportionality is a random productivity variable. Retail production requires both labor and capital. Capital is fixed and is broadly defined to include land, buildings, equipment and public infrastructure. Productivity varies across cities in both the traded goods sector and the retail sector.

Traded goods are subject to iceberg transportation costs which are good and destination specific. Final goods and local inputs (retailer labor and retail capital) are not traded beyond the city limits. While hours and consumption are both choice variables, the assumptions we make in the model imply constant hours in all sectors in all locations, reminiscent of the Long and Plosser (1983) multi-sector, closed economy, real business cycle model. Retail infrastructure, including land, capital and equipment, is in fixed supply (denoted $K_{j}$ ).

The good index, $i$, distinguishes physical objects from the identities of agents and locations only when needed to avoid confusion. In describing the flow of goods from one location to another, the source is the first subscript and the destination is the second subscript. Thus, $X_{s d}$ refers to the shipment of good $X$, from city $s$ to city $d$. Given the assumption that individuals at each location specialize, $s$ also indexes the good and the individual to whom the income flows, while $d$ indicates the expenditure side of the equation. $\tau_{s d}$ is the iceberg shipping cost from the source to the destination. Since there are no durable goods or assets in the model, adding time subscripts is innocuous: they are omitted here since the focus is on the steady-state properties of the model and long-run deviations from the LOP.

The full solution for quantities and prices is given in the appendix. This section presents the complete model and parts of the equilibrium solution relevant for pricing implications, which is the focus of our empirical work. 


\subsection{Consumers}

Agents preferences are log-additive over consumption and leisure:

$$
U\left(C_{j}^{A}, L_{j}^{A}\right) \equiv(1-\theta) \log C_{j}^{A}+\theta \log L_{j}^{A}, A=m, s
$$

$C_{j}^{A}$ is aggregate consumption and $L_{j}^{A}$ is hours of leisure, for an individual working in city $j$. There are two individuals in each city, indexed by $A=m, s$; one is engaged in the manufacture of a single good $(m)$ and the other is engaged in retailing and service activities $(s)$.

The consumption aggregate is CES over varieties of manufactured goods produced worldwide:

$$
C_{j}^{A}=\left(\sum_{i}^{M}\left(\beta_{i}\right)^{\frac{1}{\varepsilon}}\left(C_{i j}^{A}\right)^{\frac{\varepsilon-1}{\varepsilon}}\right)^{\frac{\varepsilon}{\varepsilon-1}}
$$

$C_{i j}^{A}$ is the consumption of good $i$ in city $j$ by worker of type $A ; \varepsilon>0$ is the elasticity of substitution across goods, $\beta_{i}$ is a good specific taste parameter and $M$ is the number of manufactured goods in existence. $M$ is also the number of cities given our specialization assumption.

The two agents inhabiting city $j$, maximize utility (2.1) subject to their respective budget constraints:

$$
\sum_{i} P_{i j} C_{i j}^{A} \leq W_{j}^{A} N_{j}^{A}+\varphi^{A} H_{j} K_{j}
$$

where $P_{i j}$ is the price of good $i$ in destination city $j$. These prices will be the same for all agents in the same location, but differ across locations for reasons described below. Each of the two residents of city $j$ earn labor income from their production activities and split the rental income accruing to the retail infrastructure in their city $\left(\varphi^{m}+\varphi^{s}=1\right)$, the stock of which is assumed to be fixed at $K_{j}$. The rental price of retail infrastructure is denoted $H_{j}$.

The consumer's problem may be solved in two stages. In the first stage, the consumer chooses aggregate consumption and leisure, subject to a budget and time allocation constraint. In the second stage, the consumer minimizes expenditure across goods. Here we collapse the problem to a single stage for brevity. The key equations from the solution to 
the consumer's problem are:

$$
\begin{aligned}
C_{i j}^{A} & =\beta_{i}\left(\frac{P_{i j}}{P_{j}}\right)^{-\varepsilon} C_{j}^{A} \\
C_{j}^{A} & =\frac{W_{j}^{A} N_{j}^{A}+\varphi^{A} H_{j} K_{j}}{P_{j}} \\
N_{j}^{A} & =1-\theta-\varphi^{A} \theta \frac{H_{j} K_{j}}{W_{j}^{A}} \\
L_{j}^{A} & =\theta+\varphi^{A} \theta \frac{H_{j} K_{j}}{W_{j}^{A}}
\end{aligned}
$$

Aggregate real consumption is nominal consumption deflated by the ideal deflator $P_{j} \equiv$ $\left(\sum_{i} \beta_{i}\left(P_{i j}\right)^{1-\varepsilon}\right)^{\frac{1}{1-\varepsilon}}$, which ensures $\sum_{i} P_{i j} C_{i j}=P_{j} C_{j}$ as well as a theoretical mapping from price indices to welfare.

The first equation determines consumption demand for a particular good as a function of the relative price of the good paid by the final consumer in their home market and that individual's aggregate consumption level. It is important to note that, $P_{i j}$ is the retail price of good $i$, in city $j$; it embodies the cost of local retail services paid to the retailer in addition to the traditional iceberg trade costs of the imported item. The price index, is a weighted average of these retail prices, the closest empirical counterpart would be the CPI index. The second equation is aggregate consumption of an agent, which is equal to her real income. Real income is the sum of nominal wage and rental income, deflated by the local price level, $P_{j}$.

The last two equations determine hours of work and leisure. In the absence of rental income, the two agents would work the same number of hours, independent of their relative wage, due to the offsetting income and substitution effect of wages on effort with CobbDouglas preferences. In the presence of rental income the requirement for constant effort in equilibrium is that the ratio of rental income to labor income be constant. Most growth models impose restrictions on tastes and technology to ensure constancy of hours per capita in the presence of trending productivity. ${ }^{1}$

\footnotetext{
${ }^{1}$ Details of these restrictions in the context of the one sector stochastic growth model may be found in King, Plosser and Rebelo (1988).
} 


\subsection{Manufacturers}

The production function for manufactured good, $i$, is:

$$
Y_{i}=A_{i} N_{i}^{m}
$$

where $A_{i}$ is the productivity level and $N_{i}^{m}$ is hours of work.

Manufacturers choose labor inputs to minimize costs:

$$
\min _{N_{i}^{m}}\left(W_{i}^{m} N_{i}^{m}\right) \cdot \text { subject to Equation } 2.8
$$

The manufacturer receives the factor gate price, $Q_{i i}$, for every unit produced, no matter where the goods end up being sold. Given the assumptions of constant returns to scale, perfect competition and one factor of production, the factory gate price equals the manufacturing wage divided by productivity:

$$
Q_{i i}=\frac{W_{i}^{m}}{A_{i}}
$$

Given specialization, the productivity level in this expression is good and city-specific. The presence of a nation-specific component could easily be incorporated by allowing $A_{i}$ to have a common factor across cities located within the same country.

Retailers in each city purchase the manufactured goods and pay a proportional shipping cost. Thus the retail purchase price is the factory-gate price marked up by a proportional shipping cost:

$$
Q_{i j}=\left(1+\tau_{i j}\right) Q_{i i}=\left(1+\tau_{i j}\right) W_{i}^{m} / A_{i}
$$

where $\tau_{i j}>0$ is the net transportation cost from city $i$ to $j . Q_{i j}$ is the price the retailer pays in the destination city. The empirical counterpart to this would be a wholesale price. The local manufacturing plant is close enough to the city to ignore local transportation costs so that $\tau_{i i}=0$. Effectively this cuts out one intermediary, the wholesaler, and the retailer is viewed as operating next to the factor gate. The destination price of the manufactured good depends: i) positively on both the manufacturing wage and the trade cost; and ii) negatively on manufacturing productivity. 


\subsection{Retailers}

The retailer in each city optimally chooses how much of each manufactured good to purchase from various cities of the world. The retailer transforms these goods using a fraction of her time endowment and some amount of the local retail infrastructure. The retailer then sells the resulting composite good in the local retail market. The production function for good $i$, sold in city $j$ is:

$$
R_{i j}=\left(\left(B_{j} N_{i j}^{s}\right)^{\gamma_{i}}\left(K_{i j}\right)^{1-\gamma_{i}}\right)^{1-\alpha_{i}}\left(G_{i j}\right)^{\alpha_{i}}
$$

$G_{i j}$ is the amount of the manufactured good imported from city $i$, by a retailer in city j. $\quad N_{i j}^{s}$ is the fraction of the retailer's time endowment allocated to the transformation of imported good $i$ for local consumption in city $j$ and $K_{i j}$ is the amount of retail infrastructure allocated to retail good $i$ in city $j . \quad B_{j}$ is labor-augmenting productivity specific to the city (equivalently, the retailer), common to all goods sold there. ${ }^{2}$

While the production function is restricted to be common to all locations, it is very flexible across goods. It captures pure labor services (e.g., baby-sitting services) with $\alpha_{i}$ equal to zero and $\gamma_{i}$ equal to one; internet purchases (e.g., Amazon.com book purchases), $\alpha_{i}$ equal to one, and all points in between.

The retailer in city, $j$, minimizes costs of the sale of each good, $i$, by optimally choosing the three inputs needed to produce the good: i) the amount of the traded input, $G_{i j}$, to import ii) the fraction of her time to devote to the good, $N_{i j}^{s}$; and iii) how much local infrastructure to allocate to the activity, $K_{i j}$ :

$$
\min _{N_{i j}^{s}, K_{i j}, G_{i j}}\left(W_{j}^{s} N_{i j}^{s}+H_{j} K_{i j}+Q_{i j} G_{i j}\right) \quad \text { subject to Equation } 2.12
$$

At the optimum, the unit price equals marginal cost. Given constant returns to scale and three factors of production, the retail price of good $i$ sold in location $j$, is a Cobb-Douglas aggregate of the price (inclusive of trade cost) that the retailer paid to acquire the traded

\footnotetext{
${ }^{2}$ In principle one could add good-specific productivity of retailers to account for different levels of competency across goods, but we lack productivity data to operationalize this idea.
} 
input, $Q_{i j}$, the retailer's market wage, $W_{j}^{s}$, and the rental price of retail infrastructure, $H_{j}$ :

$$
\begin{aligned}
P_{i j} & =M C_{i j}^{s}=\phi_{i}\left(\left(W_{j}^{s} / B_{j}\right)^{\gamma_{i}}\left(H_{j}\right)^{\left(1-\gamma_{i}\right)}\right)^{\left(1-\alpha_{i}\right)}\left(Q_{i j}\right)^{\alpha_{i}} \\
\phi_{i}^{-1} & \equiv \alpha_{i}^{\alpha_{i}}\left(\left(1-\alpha_{i}\right)\left(\gamma_{i}\right)^{\gamma_{i}}\left(1-\gamma_{i}\right)^{\left(1-\gamma_{i}\right)}\right)^{\left(1-\alpha_{i}\right)}
\end{aligned}
$$

The retail price in city $j$ is rising in input prices and falling in retail productivity, $B_{j}$.

\subsection{Equilibrium}

The appendix contains the tedious algebra necessary to arrive at the equilibrium allocations discussed in this section. In the remainder of the paper the consumption aggregator is restricted to Cobb-Douglas to arrive at closed form solutions.

In the global general equilibrium, all the optimality conditions of partial equilibrium must hold for consumers, retailers and manufacturers. In addition, the supply of each good must equal its total demand, including the resources lost to iceberg shipping costs.

$$
\begin{aligned}
Y_{i} & =\sum_{j} G_{i j}\left(1+\tau_{i j}\right) \\
& =\sum_{j} G_{i j}+\sum_{j} G_{i j} \tau_{i j} \\
& =G_{i}+T_{i}
\end{aligned}
$$

In words: the production of good $i, Y_{i}$, is exhausted between the global demand for that good by retailers aggregated across destinations, $G_{i}$, and physical loses due to iceberg costs, $T_{i}$.

Each individual has a fixed amount of time to devote to hours of work and leisure, here, normalized to unity. The time constraints for the manufacturers and the retailers are thus:

$$
\begin{aligned}
L_{j}^{m}+N_{j}^{m} & =1 \\
L_{j}^{s}+\sum_{i} N_{i j}^{s} & =1 .
\end{aligned}
$$

The summation in the second time constraint reflects the fact that the retailer must divide her time across all the different retailing activities. The notation implicitly sets the number

of goods at the retail level equal to the number of goods in the manufacturing sector. Nothing we derive requires this: we could have some activities that use no traded inputs at all in 
which case the number of retail goods would exceed the number of manufacturing goods by the number of pure services produced by 'retailers' in each city.

The city's retail infrastructure is exhausted across uses:

$$
K_{j}=\sum_{i} K_{i j}
$$

\section{The data}

Our focus is retail price dispersion across international cities at the microeconomic and macroeconomic level. The data source for prices is the Economist Intelligence Unit (EIU) worldwide retail price survey. The survey spans 123 cities, located in 79 countries. Most of the cities are national capitals. The larger number of cities than countries is due to the fact that the survey also includes multiple cities in a few countries. Noteworthy are the 16 U.S. cities included in the survey; the next largest number of cities surveyed equals 5 in Australia, China and Germany. Up to data availability for particular years and cities, the number of goods and services priced is 301. The available sample is 1990 to 2005 .

\subsection{Retail prices}

Our goal is to understand the sources of variation in LOP deviations. The Cobb-Douglas functional forms in our model rationalize the use of logarithms of LOP deviations across bilateral city-pairs:

$$
q_{i j k, t}=\ln \left(S_{j k, t} P_{i j, t} / P_{i k, t}\right)
$$

where $S_{j k, t}$ represents the nominal exchange rate across cities $j$ and $k$ at time $t$. Our long-run focus further suggests the use of time-averaged deviations:

$$
q_{i j k}=T^{-1} \sum_{t} q_{i j k, t}
$$

Crucini and Telmer (2007) derive a variance decomposition which is very useful for splitting the total variance of LOP deviations into long-run deviations and time series fluctuations:

$$
\begin{aligned}
\operatorname{Var}_{j k, t}\left(q_{i, j k, t} \mid i\right) & =\operatorname{Var}_{j k}\left(E_{t}\left[q_{i, j k, t} \mid i, j k\right]\right)+E_{j k}\left[\operatorname{Var}_{t}\left(q_{i, j k, t} \mid i, j k\right)\right] \\
V_{i} & =T_{i}+F_{i}
\end{aligned}
$$


The first term, $T_{i}$, which is meant to remind the reader of trade costs broadly defined, is the focus of this paper. It is the variance of the deviations from the LOP across all location pairs remaining after time-averages of the data have been taken. The role of time-averaging is to eliminate the time series component of the variation, which is valid when the data are stationary and sufficiently long time samples are available, which is the case here. The second term, $F_{i}$, which is to remind the reader of fluctuations, is the focus of the international finance literature, often featuring short-run fluctuations of LOP due to local currency price stickiness. One of the novel findings of Crucini and Telmer is that the ratio of the variance of the long-run deviations to the total (i.e., $T_{i} / V_{i}$ ) is very large for the average good: 0.51 for U.S.-Canada intranational pairs and 0.69 for all international city pairs in the EIU data. In other words, the variance component this model focuses upon is at least as important in an accounting sense as the focus of business cycle models.

One way to visualize this property of the data is to estimate LOP distributions using kernel estimation. Figure 1 has eight such kernel estimates. Each chart contains two lines, one for the distribution of time-averaged LOP, $q_{i j k}$, and one for the distribution of the time series deviations from the long-run means, $q_{i j k, t}-q_{i j k}$. The upper two charts are distributions for U.S. city pairs and the lower two are international pairs. The left column uses non-traded goods prices and the right column uses traded goods prices. The dominance of the long-run sources of variation relative to the short-run (time series) sources of variation in most cases is evident in the wider dispersion in the LOP distributions represented by the solid lines than those represented by the dashed lines in each chart. The role of borders in increasing price dispersion is evident in comparing the top and bottom panels and the role of the type of good, as summarized by the classical dichotomy, is apparent by comparing charts in a particular row across columns.

Table 1 presents summary statistics relating to these figures. The least amount of price dispersion is found in U.S. traded goods, 0.29 and the greatest amount is found in the case of non-traded goods involving border crossings, 1.07. More surprising is the fact that nontraded goods in the U.S. have less price dispersion than do traded goods internationally, 0.54 compared to 0.68 . Interquartile differences yield similar measures of price dispersion. As discovered by Crucini and Telmer (2007), the time series variation is always less than 
the long-run variance, with the possible exception of traded goods across U.S. cities and even there one of the two measures (interquartile difference) also gives this ranking. Notice also that the distinction between traded and non-traded goods is obvious in the long-run measure, but ambiguous in the time series measure. Given our emphasis on trade costs, broadly defined and abstraction from stochastic variation due to shocks interacting with sticky prices, this observation is another reason to focus on the time averaged data with our model.

\subsection{Wages and rental prices}

The EIU survey offers little in the way of wage data. Supplemental wage data at the country level come from the International Labor Organization (ILO) survey of occupational and sectoral wages and at the city level from the Union Bank of Switzerland (UBS) survey. The ILO data are averages for countries. They span 49 sectors, 162 occupations and 137 countries. The sample period is annual from 1983 to 2003. The complete list of these sectors, occupations, and countries is found in Oostendorp (2003). In the raw ILO data, the most common period is the month, followed by the hour, but some countries report weekly pay, others give daily rates for some occupations, and so on. In order to have a comparable wage data across countries, the standardized version of ILO survey by Oostendorp (2003) is used: in cases in which the wage data are reported as hourly or daily, then these wages were made (roughly) comparable with monthly wages by multiplication by 160 and 20 respectively. In

order to have the largest panel of wage data that are comparable across countries, the monthly wages in US dollars that have been obtained by country-specific and uniform calibration in Oostendorp (2003) are used.

Wage data at the city level is more appropriate given the EIU retail price data is city based and the intent of the model. International cities were surveyed by the UBS in 2006 . These are hourly wages in US dollars, spanning occupations in 71 international cities, 60 of which are also surveyed by the EIU. Among the 60 EIU cities there are four cities from Brazil, Canada, China, France, Italy, Spain and Switzerland; four cities from Germany, and four cities from the U.S. The hourly wages have been obtained by dividing the income per year in each occupation by the city level hours of work in a year, where the latter we collected 
by a survey, also conducted by the UBS.

Bureau of Labor Statistics (BLS) city wage data from the Occupational Employment Statistics (OES) Survey in 2006 are used to complement UBS data. These wage data are hourly wages in US dollars for the same 16 US cities found in EIU retail price survey. The combination of UBS and BLS wage data, then, provides wage data for 72 EIU cities, comprised of 16 from the BLS and the remainder (non-U.S. cities) from the UBS. Within these 72 EIU cities, in terms of intranational cities, we have two cities from Brazil, Canada, China, France, Italy, Spain and Switzerland; three cities from Germany, and 16 cities from the US. ${ }^{3}$

In a preliminary part of the analysis, the BLS city wage data are used for broader wage dispersion analysis. These data cover two industries, namely production and sales, for 400 cities (on average) within the U.S. in terms of hourly wages from 1999 to 2006.

A number of trade-offs present themselves in terms of the model focus and the available data. Country-level wage data is generally available for longer periods of time, but fewer locations than city-level wage data. Since the model is explicitly constructed to mimic city level aggregation and steady-state features, ideally one would want long time series at the city level. Unfortunately these are simply not available. These trade-offs are discussed as they arise below.

Land prices and rents are even more difficult to come by than are wages and prices. We use the EIU survey data item: "Typical annual gross rent for top-quality units, 2,000 square meters, suitable for warehousing or factory use." ${ }^{4}$

\subsection{Distribution costs}

The other two pieces of information are sectoral U.S. NIPA data and input-output tables, used to compare our microeconomic regression estimates of the good-specific distribution

\footnotetext{
${ }^{3}$ In an earlier version of this paper we used PWT per capita annual income data covering the annual period from 1990 to 2004 to proxy for real wages. These data span all 79 EIU countries. The results were qualitatively similar to those reported here.

${ }^{4}$ One additional commerical rental price is available in the EIU, "Typical annual gross rent for a 1,000 square meter unit in a Class A building in a prime location." Results are very similar with this alternative measure.
} 
shares, $1-\alpha_{i}$, with more direct, but quite aggregated, versions from these U.S. sources. The NIPA data extend to 57 sectors, while the input-output data span 33 sectors. The NIPA shares are computed as the value the producers receive relative to the value consumers pay for the output of a particular sector. In practice, then, the distribution margin includes transportation costs, retail and distribution costs and markups.

For the typical traded good, the distribution margin computed using the consumer value less the producer value relative to the consumer value is about $50 \%$. That is, the retail price is about twice the producer price. However for services, the same NIPA data will produce an estimate of the distribution margin close to zero. Consider a visit to the doctor's office to receive an expensive vaccine injection by a nurse. Because of the arms length nature of the transaction, it appears as though what the consumer pays, the producer gets. Most existing studies record the distribution margin to be zero for all intents and purposes in these situations. ${ }^{5}$ However, the economic concept that the distribution margin is intended to capture in our model is the distinction between locally produced inputs and international traded inputs. By this definition, the distribution margin is actually close to 1 , not 0 , in the example just described. The intent is to treat the labor services of the nurse at the doctor's office consistently with the labor services of the salesperson at Walmart. Similarly, the rent paid by the Walmart franchisee and the user's cost of the hospital are also part of the distribution margin and are also treated the same way.

Finally, the greater circle distance between cities in the EIU sample is used to estimate the trade cost component of the LOP deviations at the retail level. ${ }^{6}$

\footnotetext{
${ }^{5}$ See, for example, Burstein, Neves and Rebelo (2003). Following a conversation between Crucini and Rebelo, the distribution margin in Burstein, Eichenbaum and Rebelo (2005, 2007) makes an approximate correction for this effect.

${ }^{6}$ Hummels (2001) provides the most comprehensive estimates of sectoral trade costs using import unit values, a more direct method than employed here. Unfortunately these estimates are available for a limited number of countries and are more aggregated than our retail data.
} 


\section{Microeconomic sources of long-run variation in wages}

In the model, wage deviations arise across the retail and manufacturing sectors and across cities. The amount of labor income accruing to the manufacturer relative to the retailer in city $j$ is,

$$
\frac{N_{j}^{m} W_{j}^{m}}{N_{j}^{s} W_{j}^{s}}=\frac{\sum_{i} \alpha_{i} \beta_{i}}{\sum_{i}\left(1-\alpha_{i}\right) \gamma_{i} \beta_{i}}
$$

Which is intuitive: the numerator is an expenditure share weighted average of labor's share of manufacturing and the denominator is the counterpart in retailing. The appearance of the parameter $\gamma_{i}$ in the denominator accounts for the fact that retail production involves some retail infrastructure, unless $\gamma_{i}=1$, in which case retail production is labor-only. Note, also, that the ratio is the same in all cities.

As the primary interest is wage variation across cities as an explanation for cost and price variation across cities, we would like to understand the wage ratio and effort ratios separately. The equilibrium relative sectoral wage is given by:

$$
\frac{W_{j}^{m}}{W_{j}^{s}}=\frac{\varphi^{m}}{1-\varphi^{m}} \frac{(1-\theta)-N_{j}^{s}}{(1-\theta)-N_{j}^{m}}
$$

Thus, given fixed shares of rental income across agents in the city, relative wages and relative hours move inversely as one would expect. The appendix shows that the equilibrium effort levels are:

$$
\begin{aligned}
N_{j}^{m} & =\frac{\left(1-\phi_{0}\right)(1-\theta)}{\left(1-\phi_{0}\right)+\varphi^{m} \theta\left(\phi_{0}-\phi_{1}\right)} \\
N_{j}^{s} & =\frac{\phi_{1}(1-\theta)}{\phi_{1}+\varphi^{s} \theta\left(\phi_{0}-\phi_{1}\right)}
\end{aligned}
$$

where $\phi_{0} \equiv \sum_{i}\left(1-\alpha_{i}\right) \beta_{i}$ and $\phi_{1} \equiv \sum_{i}\left(1-\alpha_{i}\right) \gamma_{i} \beta_{i}$. Effort in both sectors is declining in the share of rental income allocated to the agent (a wealth effect), and in the preference for leisure $(\theta)$, as one would expect.

Substituting these expressions into the wage ratio leads to the following expression for relative wages:

$$
\frac{W_{j}^{m}}{W_{j}^{s}}=\frac{1-\varphi^{m}}{\varphi^{m}} \frac{\left(1-\phi_{0}\right)+\varphi^{A} \mu}{\phi_{1}+\left(1-\varphi^{A}\right) \mu}
$$


$\mu=\theta\left(\phi_{0}-\phi_{1}\right)$.

As the retail sector becomes more labor intensive (thus reducing rental income), $\left(\phi_{0}-\phi_{1}\right)$ converges to zero and the model reverts to the labor-only version with a common fraction of available hours worked by both agents, equal to $(1-\theta)$ and the sectoral wage ratio converges to:

$$
\frac{W_{j}^{m}}{W_{j}^{s}}=\frac{1-\phi_{0}}{\phi_{0}}=\frac{\sum_{i} \alpha_{i} \beta_{i}}{\sum_{i}\left(1-\alpha_{i}\right) \beta_{i}}
$$

which is exactly the same expression as labor income shares in the more general case (see equation (4.1)).

Turning to wage differences across cities things are much simpler even in the general case:

$$
\begin{aligned}
\frac{W_{j}^{s}}{W_{k}^{s}} & =\frac{\alpha_{j} \beta_{j}}{\alpha_{k} \beta_{k}} \\
\frac{W_{j}^{m}}{W_{k}^{m}} & =\frac{\alpha_{j} \beta_{j}}{\alpha_{k} \beta_{k}} .
\end{aligned}
$$

The cross-city wage differential is the same in both sectors and is determined by the product of the taste and technology parameters in the two locations being compared. The intuition for this result is as follows. Consider, first, the special case in which all goods use traded inputs in the same proportion, $\alpha_{j}=\alpha$. Wages are higher in locations that produce the goods most preferred by consumers, given by the comparison of $\beta_{j}$ and $\beta_{k}$, a demand-side effect. Next, consider the case with symmetric tastes across goods $\beta_{j}=\beta$; then wages are the highest for producers of manufactures requiring the least amount of input from retailers (i.e., the lowest $1-\alpha$ ). Essentially, the higher the distribution share, the less productive is an hour allocated to production of the manufactured good in terms of delivering a unit of consumption to final consumers. This lowers the equilibrium real wage.

Wage data are available by occupation or sector of employment. Our model focuses on the distinction between goods and services, suggesting the production sector definition is more appropriate. However, we use both labor classifications as a robustness check.

The more comprehensive of the sources used is the ILO survey of wage levels across countries. These data span 49 sectors, 162 occupations and 137 countries. The sample period is annual from 1983 to $2003 .^{7}$ Because the model is intended to be based on city-level

\footnotetext{
${ }^{7}$ Useful technical documentation is found in Remco H. Oostendorp (2003).
} 
data, the preferred measure is wage data from the UBS that span 14 occupations and 71 international cities for the year 2006.

According to the model, if the retail sector uses only labor and traded goods, the ratio of manufacturing wages to service wages provides on estimate of the overall scale of the distribution sector $W_{j}^{m} / W_{j}^{s}=\kappa / 1-\kappa, \kappa=\sum_{i} \beta_{i} \alpha_{i}$. Since we lack consumption expenditure shares at the present time, we associate this with the distribution share alone since using the symmetric taste version of the model we have: $\kappa=\bar{\alpha}$. A direct way to measure the overall size of the distribution sector is to use U.S. NIPA data and input-output data. Crucini and Shintani (2008) do exactly this and find $\kappa=0.57$. The advantage of their calculation is that is it based on expenditure weighting of sectoral $\alpha$ 's.

Table 2 reports the sectoral wage ratio averaged across locations as well as the implied value for $\kappa$. It turns out that the direct and indirect (model-based) estimates are equal when U.S. wages in production sector relative to the sales sector are used. The wage ratio in the international data is consistent with a value $\kappa$ of 0.52 . While this is a modest difference from the U.S. value, the implied manufacturing wage premium is quite dramatically affected: it is a factor of 5 smaller than the U.S. case. It could be that relative productivity differences are the cause. Another possibility is that the U.S. and international agencies have different classification systems for the sectors.

As the theory is a two-sector model, any sectoral variation in wages in a particular city is attributable to wage differences across the manufacturing and service sectors. Variation in wages across sub-sectors are abstracted from entirely. Thus, it is important for the theory that wages differ significantly across locations and less so across sectors other than the two sectors emphasized by the model (retail and manufacturing). And this is what is found.

Table 3 conducts a variance decomposition by sector and country for time-averaged wages in the case of the ILO survey and an analogous decomposition by sector and city for wages in 2006 for the UBS survey data. Since the answer may depend on the set of sectors and locations used, we consider three location groups and allow for many sectors throughout. The location groups are the entire world, the OECD and the LDC.

Based on the ILO wage data: locations account for between 72 and 85 percent of the cross-sectional variation in wages, sectoral differences account for less than 10 percent. The 
dominance of location in accounting for wage dispersion is somewhat less pronounced when the data is organized by occupation: location effects drop to between 38 and 65 percent. Most of difference is not attributed to a pure sectoral component, but rather an interaction of location and sector. The UBS tell a similar story to the ILO for location effects, with the occupation effect rising in contribution due to a lower interaction with location compared to the ILO.

In sum, location is a key component of wage dispersion with the precise fractions depending somewhat on the set of locations examined and the precise definition of wage categories.

\section{Microeconomic sources of long-run variation in real exchange rates}

We turn, now, to the main focus, price dispersion. In the model, prices consumers actually pay may differ from factory gate prices for two reasons. The first is the trade cost to import the good from the foreign production location. The second is the value added by the retailer. To simplify the notation, all international prices have been converted to common currency units (it does not matter which numeraire is chosen). The ratio of the price of good $i$ in city $j$ relative to $k$, based on the theory is:

$$
\frac{P_{i j}}{P_{i k}}=\left(\frac{W_{j}^{s} / B_{j}}{W_{k}^{s} / B_{k}}\right)^{\gamma_{i}\left(1-\alpha_{i}\right)}\left(\frac{H_{j}}{H_{k}}\right)^{\left(1-\gamma_{i}\right)\left(1-\alpha_{i}\right)}\left(\frac{Q_{i j}}{Q_{i k}}\right)^{\alpha_{i}} .
$$

Noting that the last term reduces to the ratio of trade costs from the single source of good $i$ to each of the destinations, $j$ and $k$ and taking logs, defines the Law-of-One-Price deviation across a city pair:

$$
\begin{aligned}
q_{i j k} & =\left(1-\alpha_{i}\right)\left[\gamma_{i} \omega_{j k}+\left(1-\gamma_{i}\right) h_{j k}\right]+\alpha_{i} \tau_{i j k} \\
& =\rho_{i} \omega_{j k}+\chi_{i} h_{j k}+\alpha_{i} \tau_{i j k} .
\end{aligned}
$$

The retail margin is the first term in square braces; it is a weighted average of the productivityadjusted wage and the rental price differential faced by retailers in the two cities. The weights attached to the relative input prices in the retail sector depend on $\gamma_{i}$. The entire retail component gets weighted by its overall share in the production of the final good, $\left(1-\alpha_{i}\right)$. The 
second term is the relative trade cost. The last line, used to specify our regression approach, expresses the relationship in terms of the three key cost ratios, retail wages, rental prices and trade costs.

\subsection{Regression specification}

This section conducts a variance decomposition of retail prices into the channels described by the equilibrium model. Adding a measurement error term to the theoretical equation for the LOP deviation, gives:

$$
q_{i j k}=\rho_{i} \omega_{j k}+\chi_{i} h_{j k}+\alpha_{i} \tau_{i j k}+\varepsilon_{i j k}
$$

Data on retail prices, wages and rent, are available, but no data on retail productivity or trade costs exist for this cross-section of locations, at this level of disaggregation. The raw wage ratios are used in place of $\omega_{j k}$ and a two-stage estimation approach is used to infer the impact of trade costs.

The first-stage regression is:

$$
q_{i j k}=\rho_{1 i} \omega_{j k}+\chi_{1 i} h_{j k}+\theta_{i j k} .
$$

where $\theta_{i j k}$ is an estimated residual, which, according to the theory, is the LOP deviation in the traded component of cost. In practice it will incorporate other sources of deviations as well. In an attempt to purge these other factors from the pure trade cost component, the estimated residuals are projected on bilateral distances. To accomplish this, define the direction-of-trade indicator function:

$$
\mathbf{I}_{i j k}=\left\{\begin{array}{cc}
1 & \text { if } \theta_{i j k}>0 \\
-1 & \text { if } \theta_{i j k}<0
\end{array}\right.
$$

where $\theta_{i j k}=q_{i j k}-\rho_{1 i} \omega_{j k}-\chi_{1 i} h_{j k}$ from the first-stage regression. In words: imports (exports) are assumed to be relatively expensive (inexpensive) at the destination (source). 
Consider, now, the more elaborate equation for stage two:

$$
\begin{aligned}
q_{i j k} & =\rho_{2 i} \omega_{j k}+\chi_{2 i} h_{j k}+\varsigma_{i 2} \mathbf{I}_{i j k} d_{j k}+\varepsilon_{i j k} \\
\rho_{2 i} & =\left(1-\alpha_{i}\right) \gamma_{i} \\
\chi_{2 i} & =\left(1-\alpha_{i}\right)\left(1-\gamma_{i}\right) \\
\varsigma_{2 i} & =\alpha_{i} \delta_{i}
\end{aligned}
$$

with the trade cost replaced by $\mathbf{I}_{i j k} \delta_{i} d_{j k}$. The indicator function ensures the sign of the implied trade cost is consistent with the sign of the residual estimated in stage one. The greatest circle distance between locations $j$ and $k$ is the empirical counterpart to $d_{j k}$ and goods are allowed to have different trade cost elasticities with respect to distance, $\delta_{i}$. The benefit of projecting the prices on wages, rents, and the indicator function multiplying distance is that we relegate any sources of variation in retail prices not correlated with wages, rental prices or distance to the error term. This gives us more confidence that the wage, rental, and trade cost components are capturing what the model says they should.

The model is best suited to describe the long-run properties of real exchange rates since we abstract from nominal exchange rate variation and sticky prices. While we have a long panel of EIU retail price data from which to construct time-averages and target long-run price dispersion, as noted earlier, we lack comparable city-level panel data on wages. Moreover, the argument could be made for estimating the parameters with a single cross-section. Our benchmark estimation and variance decomposition uses time-average data as available (i.e., for $q_{i j k}$ and $\left.h_{j k}\right)$ and wage data for a single cross-section in 2006. Wage data from the UBS is used for cities outside of the U.S. and wage data from the BLS is used for U.S. cities. Preliminary experimentation with alternatives does not seem to alter the main thrust of the results.

We see in Table 4, that the empirical model captures the majority of long-run retail price dispersion across locations for all groupings of the data. The range of variance accounted for is between 70 percent and 90 percent for the median good when pooling all international cities or just those in North America. The fit of the model is excellent over much of the distribution of goods. The lowest quartile for the $R^{2}$ is a very respectable 0.67 (the OECD cross-border pairs). In summary, the empirical model fits well across sub-set of locations 
and across goods ranging from haircuts to personal computers.

\subsection{Variance Decomposition}

Using the estimated equations motivated by the theory, we are able to provide a crosssectional variance decomposition analysis according to the following equation (we suppress the residual and covariance terms here for expositional convenience; also the parameters used in computations will be those from the second stage estimation, though we suppress the subscript denoting this as well in what follows):

$$
\operatorname{var}_{j k}\left(q_{i j k}\right)=\left(1-\alpha_{i}\right)^{2} D_{i j k}+\alpha_{i}^{2} d_{i j k}
$$

According to the theory, geographic price dispersion at the level of an individual good, $i$, is a weighted average of the geographic dispersion in distribution costs, $D_{i j k}$, and the geographic dispersion of destination prices for traded inputs, $d_{i j k}$. The relative contribution

of distribution costs and trade costs for a particular good hinges on the value taken by the distribution share, $\alpha_{i}$, ranging from close to zero for a personal computer to close to 1 for a haircut.

Recall that the distribution cost component is a weighted average of the dispersion in wages and rental prices:

$$
D_{i j k} \equiv\left[\gamma_{i}^{2} \operatorname{var}_{j k}\left(\omega_{j k}\right)+\left(1-\gamma_{i}\right)^{2} \operatorname{var}_{j k}\left(h_{j k}\right)\right]
$$

Finally, the quantitative role of trade costs depends on the relationship between trade costs and distance interacting with the direction of trade:

$$
d_{i j k}=\delta_{i}^{2} \operatorname{var}_{j k}\left[\mathbf{I}_{i j k} d_{j k}\right]
$$

Table 5 presents estimates of the variances of retail prices, wages and rental prices for various location groups: i) intranational city pairs (which given the data, is dominated by U.S. city pairs), and ii) cross-border city pairs (using three groupings, OECD, LDC and World).

The conventional wisdom is that factor markets are close to perfectly integrated intranationally, while the immobility of labor and possibly capital prevents this from occurring 
internationally. This seems to be a reasonable assumption of labor markets since we find wage dispersion of 3 or 4 percent, for intranational pairs. It appears not to be true of rental prices, where dispersion is about 30 percent. These numbers are fairly robust of inclusion of intranational city pairs outside of North America.

Turning to cross-border city pairs, consistent with expectations, we see less of a tendency toward factor-price equalization than within countries. In fact, there is an approximate tripling of the variance of wages as a consequence of crossing the U.S.-Canadian border. The border width appears less dramatic when we look at rental prices, where the variance merely doubles. When we expand the set of international comparisons to the OECD, we find virtually no impact on wage dispersion beyond what the U.S.-Canadian border implies, but a large impact on rental price dispersion. Expanding the geography further to include both the OECD and non-OECD (the row labelled WORLD), wage dispersion increases considerably more than rental price dispersion. The main implication for retail price dispersion, though, is that factor price dispersion rises by a factor of about 30 for both wages and rental prices as we move from intranational city pairs to a broad cross-section of international city pairs. Distribution costs, therefore, are expected to be significant contributors to the absolute level of LOP deviations at the retail level, particularly for cross-border pairs since factor prices are far from being equalized internationally. Moreover, the relative contribution of distribution costs relative to trade costs will shift across goods according to the distribution share parameter, $\alpha_{i}$.

We turn now to the details of the variance decomposition. The analysis considers both a variance decomposition for the median good and results good-by-good. In each case we contrast interesting geographic groups. For the discussion that follows, it is useful to refer to the full variance decomposition:

$$
\begin{aligned}
\operatorname{var}_{j k}\left(q_{i j k}\right)= & {\left[\left(1-\alpha_{i}\right) \gamma_{i}\right]^{2} \operatorname{var}_{j k}\left(\omega_{j k}\right)+\left[\left(1-\alpha_{i}\right)\left(1-\gamma_{i}\right)\right]^{2} \operatorname{var}_{j k}\left(h_{j k}\right)+\left(\alpha_{i} \delta_{i}\right)^{2} \operatorname{var}_{j k}\left[\mathbf{I}_{i j k} d_{j k}\right] } \\
& +\operatorname{var}_{j k}\left[\varepsilon_{i j k}\right]+\mathrm{cov} \text { terms }
\end{aligned}
$$

Consider a good which uses no traded inputs at the retail level $\left(\alpha_{i}=0\right)$. The prediction simplifies reduces to:

$$
\operatorname{var}_{j k}\left(q_{i j k}\right)=\gamma_{i}^{2} \operatorname{var}_{j k}\left(\omega_{j k}\right)+\left(1-\gamma_{i}\right)^{2} \operatorname{var}_{j k}\left(h_{j k}\right)+\text { cov terms }
$$


We key insight here, is that price dispersion is entirely due to retail costs associated with wage and rental price dispersion, $\operatorname{var}_{j k}\left(\omega_{j k}\right)$ and $\operatorname{var}_{j k}\left(h_{j k}\right)$, respectively. These numbers naturally depend on the locations pooled in the estimation for the reasons discussed earlier. Borders matter.

At the opposite end of the continuum is a good with no retail costs at all (e.g., a good available on the internet that trades up to a shipping cost everywhere in the world $\left(\alpha_{i}=1\right)$ ). Now the expression for the predicted price dispersion reduces to:

$$
\operatorname{var}_{j k}\left(q_{i j k}\right)=\delta_{i}^{2} \operatorname{var}_{j k}\left[\mathbf{I}_{i j k} d_{j k}\right]
$$

This is an intriguing expression. The coefficient out front is the elasticity of trade cost with respect to distance (recall, the empirical model assumes a log-linear proportional trade cost function as is typical in the gravity literature). The variance of distance is a function of the set of locations under examination. As bilateral distance become less symmetric (less equal), trade cost matters more for price deviations.

The variance decomposition results are given in Table 6. For the median good, distribution costs account for between 5 and 20 percent of overall price dispersion, depending on the locations used. The wage component tends to account for more of this dispersion than the rental component. An exception is the LDC group where the rental component accounts for 12.6 percent of the dispersion, compared to only 2.5 percent for wages. Trade costs dominate the picture throughout the table, accounting for as much as 60 percent of the price dispersion for cross-border OECD pairs, to a lower, but still very substantial, 36.1 percent across the Canada-U.S. border.

Variation across goods within the cross-section, is interesting. Figure 2 shows the variance decomposition at the individual good level as a function of the traded input share, $\alpha_{i}$. To make these easier to read we have smoothed the profiles by taking centered moving averages of the variance share across 10 goods. Starting with all international cross-border pairs and the good with the lowest traded input share (roughly 0.4), wage dispersion accounts for about 45 percent of price dispersion. As we move to goods with the highest traded input share (roughly 0.97), wage dispersion accounts for almost none of the price dispersion. Of course if this good had literally no non-traded inputs the contribution would necessarily 
be exactly zero. The OECD group tells a similar story with about 30 percent of price dispersion accounted for by wage dispersion at one end of the continuum of goods and less than 10 percent contributed for goods embodying mostly traded inputs. The Canada-U.S. pairs have a lower contribution from wage dispersion as we would expect given the similar wage levels of the two countries, the contribution of this component also declines as $\alpha$ rises, though not as smoothly as the other groups. In most cases, the falling contribution of wage differences is associated with a rising role for trade costs. The intranational pairs show less heterogeneity in the proportion of variance explained by various components as the trade share of final good production varies. Partly this reflects the lower variance of wages and rent across cities within countries. Nonetheless, the contribution of distribution costs is not negligible for the intranational pairs either.

Figure 3 displays the same variance decomposition by good plotted against the labor share of total retail cost, $\gamma_{i}$. We see the dramatic effect of this parameter on the split of distribution margin variance across labor and rent. As we move across goods based on this parameter, the contribution of rent goes from zero to about 40 percent in the Canada-U.S. panel and from zero to about 20 percent in the world grouping (for cross-border city pairs). The contribution of wage dispersion tends to follow the same pattern in reverse, maintaining the total share of price dispersion due to distribution costs. The OECD is anomalous in the sense that the distribution share contributes about 10 percent without much variation across goods until we reach very high labor intensities in distribution. Turning to the intranational pairs, the overall contribution of wage dispersion is rising in its cost share as one would expect.

The results for the median good in the EIU cross-section seem to downplay the role of distribution costs relative to trade costs. Given the dramatic differences in the distribution share across goods, a natural question that arises is how representative the EIU sample is of the CPI basket. We check this by comparing the average estimated value of the distribution share across goods in the EIU with the average value implied by the U.S. NIPA shares. To accomplish this, each good in the EIU panel is placed into a sector found in the U.S. NIPA. The average estimated distribution share is 0.2 , significantly below, 0.5 , the average value across goods based on sectoral U.S. NIPA shares for the matched sample. 
To account for this estimation bias and make the results relevant for aggregate consumption, we recompute our variance decomposition using goods with distribution shares in the neighborhood of $\alpha=0.5$, the expenditure weighted average of the distribution shares found in the U.S. NIPA data. What we do is average the decomposition results across 5 goods on either side of this value. Table 7 reports these findings. We see that the contribution of the distribution margin is much more significant. Wage dispersion alone now accounts for more than one-third of retail price dispersion when all cross-border city pairs are pooled (WORLD). The role of wages for the OECD and LDC groupings is more limited suggesting the city pairs that straddle high and low income countries are the reason for the much elevated wage component. It is interesting to note that for the Canada-U.S. pairs, wage dispersion plays a significant role as well. Keep in mind, however, that the absolute dispersion of prices across North American cities is about one-fifth of that existing across cities of the world, thus the significant role of wage dispersion in North America is partly due to the fact that there is little in the way of price dispersion to explain in North America relative to the broader international sample.

\section{Conclusions}

Consumers face prices that are to a varying degree, location-specific. Our model of production and distribution across cities shows how these differences are shaped by the distances separating cities due to trade costs, the good-specific share of retail distribution and its division of these costs between labor and land. While we found trade costs dominated distribution costs by a factor of 5 to 1 for the median good in the sample, their relative contribution varies greatly across goods. For final goods that involve mostly non-traded inputs, distribution margins dominate trade costs. Given that most of the goods in the EIU have low distribution shares, these unweighted averages significantly understate the role of distribution margins in the aggregate consumption basket. Using the aggregate distribution

share and estimates of the variance decomposition for individual goods with that share, the tables are turn: distribution costs now dominate trade costs.

Our results are subject to an important caveat, which is pervasive throughout the existing 
literature. The theory attributes a significant role to local rental prices and wage rates in determining retail distribution costs and this is supported by our empirical findings. We have employed measures of service sector wages per hour and land prices per square foot, down to the level of cities. The theory requires these factor costs to be evaluted per unit sold for each good, at the retail level. To acheive this would require adjustments of raw factor input prices to account for labor productivity variation and infrastructure utilization rates, which are simply not currently available. The downward bias of our regression estimates of good-by-good distribution shares may reflect this measurement error and while this bias may actually help to improve our estimates of how factor price dispersion translates into retail price dispersion relative to a pure calibration exercise, more direct evidence would be reassuring. ${ }^{8}$ Until these empirical hurdles are fully met, the literature will have difficulty confidently ascribing geographic retail price dispersion to the real costs of distribution versus other competing theories. Much remains to be done.

\section{References}

Alessandria, George. 2004. "International Deviations From the Law-of-One-Price: The Role of Search Frictions and Market Share." International Economic Review 45(4): 12631291.

Alessandria, George and Joseph Kaboski. 2007. "Pricing-to-Market and the Failure of Absolute PPP." Federal Reserve Bank of Philadelphia Working Paper No. 01-17.

Alvarez, Fernando and Robert E. Lucas. 2007. "General Equilibrium of the EatonKortum Model of International Trade." Journal of Monetary Economics, 54(6): 1726-1768.

Atkeson, Andrew and Burstein, Ariel. 2007. "Pricing-to-Market in a Ricardian Model of International Trade," American Economic Review, 97(2): 362-367.

Burstein, Ariel, Joao Neves and Sergio Rebelo. 2003. "Distribution Costs and Real Exchange Rate Dynamics During Exchange-Rate Based Stabilizations," Journal of

\footnotetext{
${ }^{8}$ The differences between the regression estimates of the distribution share and the direct NIPA measure is not due to a few outliers: 151 out of 160 regression coefficients values are below their NIPA counterparts. The least squares estimates and the NIPA measures of the distribution shares, are, however, strongly positively correlated in the cross-section.
} 
Monetary Economics, 50(6): 1189-1214.

Burstein, Ariel, Martin Eichenbaum and Sergio Rebelo. 2005. "Large Devaluations and the Real Exchange Rate," Journal of Political Economy, 113(4): 742-784.

Burstein, Ariel, Martin Eichenbaum and Sergio Rebelo. 2007. "Modeling Exchange Rate Passthrough After Large Devaluations." Journal of Monetary Economics, 54(2): 346-368.

Choi, Yo Chul, David Hummels and Chong Qiang. 2009. "Explaining Import Quality: The Role of Income Distribution." Journal of International Economics, 77(2): 265275 .

Crucini, Mario J., Chris I. Telmer and Marios Zachariadis. 2005. "Understanding European Real Exchange Rates." American Economic Review, 95(3): 724-38.

Crucini, Mario J. and Motostugu Shintani. 2008. "Persistence in Deviations from the Law-of-One-Price: Evidence from Micro-Data." Journal of Monetary Economics, 55(3): 629-644.

Crucini, Mario J. and Telmer, Chris I. 2007. "Microeconomic Sources of Real Exchange Rate Variation." Unpublished manuscript.

Eaton, Jonathan and Samuel Kortum. 2002. "Technology, Geography and Trade." Econometrica, 70(5):1741-1779.

Giri, Raul. 2009. "Local Costs of Distribution, International Trade Costs and Micro Evidence on the Law of One Price." Unpublished manuscript.

Hummels, David. 2001. "Toward a Geography of Trade Costs." Unpublished manuscript.

King, Robert K., Charles I. Plosser and Sergio Rebelo. 1988. "Production, Growth and Business Cycles: I. The Basic Neoclassical Model." Journal of Monetary Economics, 21(2-3): 195-232.

Long, John and Charles I. Plosser. 1983. "Real Business Cycles." Journal of Political Economy, 91: 39-69.

Naknoi, K. 2008. "Real Exchange Rate Fluctuations, Endogenous Tradability and Exchange Rate Regimes." Journal of Monetary Economics, 55: 645-663.

Oostendorp, Remco H. (2003), "The Standardized ILO October Inquiry 1983-2003," 
Free University Amsterdam, Tinbergen Institute, Amsterdam Institute for International development. Unpublished. 
Table 1. Kernel Density Summary Results

\begin{tabular}{|c|c|c|c|c|}
\hline & \multicolumn{4}{|c|}{ Long-run LOP deviations } \\
\hline & Standard & Interquartile & First & Third \\
\hline & Deviation & Range & Quartile & Quartile \\
\hline \multicolumn{5}{|l|}{ U.S. cities } \\
\hline Traded goods & 0.294 & 0.385 & -0.161 & 0.224 \\
\hline Non-traded goods & 0.543 & 0.616 & -0.250 & 0.366 \\
\hline \multicolumn{5}{|l|}{ International cities } \\
\hline Traded goods & 0.681 & 0.796 & -0.365 & 0.431 \\
\hline \multirow[t]{4}{*}{ Non-traded goods } & 1.069 & 1.092 & -0.497 & 0.595 \\
\hline & \multicolumn{4}{|c|}{ Short-run LOP deviations } \\
\hline & Standard & Interquartile & First & Third \\
\hline & Deviation & Range & Quartile & Quartile \\
\hline \multicolumn{5}{|l|}{ U.S. cities } \\
\hline Traded goods & 0.250 & 0.295 & -0.151 & 0.144 \\
\hline Non-traded goods & 0.258 & 0.295 & -0.151 & 0.144 \\
\hline \multicolumn{5}{|l|}{ International cities } \\
\hline Traded goods & 0.412 & 0.417 & -0.209 & 0.209 \\
\hline Non-traded goods & 0.488 & 0.430 & -0.215 & 0.215 \\
\hline
\end{tabular}

Note: Long-run LOP deviations are time-averaged LOP deviations, short-run LOP deviations are the difference between the raw LOP series and the long-run means. 
Table 2. Mean sectoral wage differentials

\begin{tabular}{lcr}
\hline \hline & $W_{j}^{m} / W_{j}^{s}$ & Implied $\kappa$ \\
\hline World Manufacture to Sales (ILO) & 1.07 & 0.52 \\
& & \\
U.S. Production to Sales (BLS) & 1.34 & 0.57 \\
\hline Note: For details on the data sources, see the data section.
\end{tabular}


Table 3. Variance of wage differentials across sectors and locations

\begin{tabular}{|c|c|c|c|c|c|c|}
\hline & \multicolumn{3}{|c|}{ Industry (ILO) } & \multicolumn{3}{|c|}{ Occupation (ILO) } \\
\hline & Location & Sector & Error & Location & Sector & Error \\
\hline \multicolumn{7}{|l|}{ World } \\
\hline Proportion of variance & 0.85 & 0.04 & 0.10 & 0.65 & 0.01 & 0.34 \\
\hline Observations & 46 & 19 & & 136 & 113 & \\
\hline \multicolumn{7}{|l|}{ OECD } \\
\hline Proportion of variance & 0.84 & 0.06 & 0.10 & 0.64 & 0.03 & 0.33 \\
\hline Observations & 27 & 12 & & 26 & 113 & \\
\hline \multicolumn{7}{|l|}{$\mathrm{LDC}$} \\
\hline Proportion of variance & 0.72 & 0.08 & 0.20 & 0.38 & 0.04 & 0.58 \\
\hline Observations & 36 & 19 & & 109 & 113 & \\
\hline & & & & \multicolumn{3}{|c|}{ Occupation (UBS) } \\
\hline \multicolumn{7}{|l|}{ World } \\
\hline Proportion of variance & & & & 0.66 & 0.19 & 0.15 \\
\hline Observations & & & & 56 & 14 & \\
\hline \multicolumn{7}{|l|}{ OECD } \\
\hline Proportion of variance & & & & 0.51 & 0.31 & 0.18 \\
\hline Observations & & & & 32 & 14 & \\
\hline \multicolumn{7}{|l|}{$\mathrm{LDC}$} \\
\hline Proportion of variance & & & & 0.48 & 0.29 & 0.23 \\
\hline Observations & & & & 24 & 14 & \\
\hline
\end{tabular}

Notes: A panel has been selected such that the total number of observations is maximized. 
Table 4. Explanatory power

\begin{tabular}{lccc}
\hline \hline \multicolumn{2}{c}{ First quartile } & Median & Third quartile \\
\hline \multicolumn{2}{c}{ Panel A: International cities, } & cross-border pairs \\
CANADA-US & 0.83 & 0.90 & 0.94 \\
OECD & 0.67 & 0.71 & 0.74 \\
LDC & 0.70 & 0.73 & 0.75 \\
WORLD & 0.69 & 0.72 & 0.75 \\
& & & \\
& & & \\
CANADA-US & 0.72 & 0.77 & 0.81 \\
OECD & 0.71 & 0.76 & 0.79 \\
WORLD & 0.70 & 0.75 & 0.79 \\
LDC & 0.70 & 0.73 & 0.75 \\
\hline \hline
\end{tabular}


Table 5. Variance of prices across locations

\begin{tabular}{lccc}
\hline \hline & \multicolumn{2}{c}{ Retail } & \multicolumn{2}{c}{ Rental } \\
& Prices & Wages & Prices \\
\hline \multicolumn{4}{c}{ Panel A: International cities, } \\
CANADA-US & 0.07 & 0.13 & 0.61 \\
OECD & 0.25 & 0.17 & 3.05 \\
LDC & 0.42 & 0.59 & 11.18 \\
WORLD & 0.38 & 1.15 & 9.49 \\
\multicolumn{1}{c}{ Panel B: Intranational cities, no border } & \\
CANADA-US & 0.06 & 0.04 & 0.33 \\
OECD & 0.06 & 0.03 & 0.27 \\
LDC & - & - & - \\
WORLD & 0.07 & 0.03 & 0.28 \\
\hline
\end{tabular}


Table 6. Variance Decomposition (median across goods, $\alpha=0.8$ )

\begin{tabular}{lrrrrrr}
\hline \hline & Total & \multicolumn{5}{c}{ Fraction of variance account for by: } \\
\cline { 3 - 7 } & \multicolumn{7}{c}{ Wages } & Rental Prices & Trade cost & Error & Covariance \\
\hline \multirow{7}{*}{ CANADA-US } & 0.07 & 10.1 & 7.8 & 36.1 & 12.8 & 15.5 \\
OECD & 0.25 & 2.3 & 1.7 & 60.0 & 29.4 & 0.8 \\
LDC & 0.42 & 2.5 & 12.6 & 53.9 & 27.2 & 0.4 \\
WORLD & 0.38 & 7.7 & 3.4 & 50.7 & 28.1 & 5.1 \\
& & Panel B: Intranational cities, no border & & \\
CANADA-US & 0.06 & 4.8 & 5.9 & 53.8 & 24.8 & 2.3 \\
OECD & 0.06 & 5.1 & 3.7 & 51.4 & 26.5 & 3.0 \\
LDC & - & - & - & - & - & - \\
WORLD & 0.07 & 5.2 & 4.9 & 55.8 & 26.1 & 1.7 \\
\hline
\end{tabular}


Table 7. Variance Decomposition (aggregate $\alpha=0.5$ )

\begin{tabular}{|c|c|c|c|c|c|}
\hline & \multirow[t]{2}{*}{ Total } & \multicolumn{4}{|c|}{ Fraction of variance account for by: } \\
\hline & & Wages & Rental Prices & Trade cost & Error \\
\hline \multicolumn{6}{|c|}{ Panel A: International cities, cross-border pairs } \\
\hline CANADA-US & 0.10 & 31.8 & 16.6 & 38.5 & 13.1 \\
\hline OECD & 0.36 & 10.7 & 6.2 & 54.6 & 28.5 \\
\hline LDC & 0.75 & 15.2 & 16.7 & 45.7 & 22.4 \\
\hline WORLD & 0.66 & 36.4 & 6.8 & 36.0 & 20.9 \\
\hline \multicolumn{6}{|c|}{ Panel B: Intranational cities, no border } \\
\hline CANADA-US & 0.12 & 10.0 & 8.5 & 57.2 & 24.3 \\
\hline OECD & 0.13 & 6.6 & 11.0 & 56.0 & 26.3 \\
\hline \multicolumn{6}{|l|}{$\mathrm{LDC}$} \\
\hline WORLD & 0.10 & 8.6 & 6.3 & 59.7 & 25.4 \\
\hline
\end{tabular}



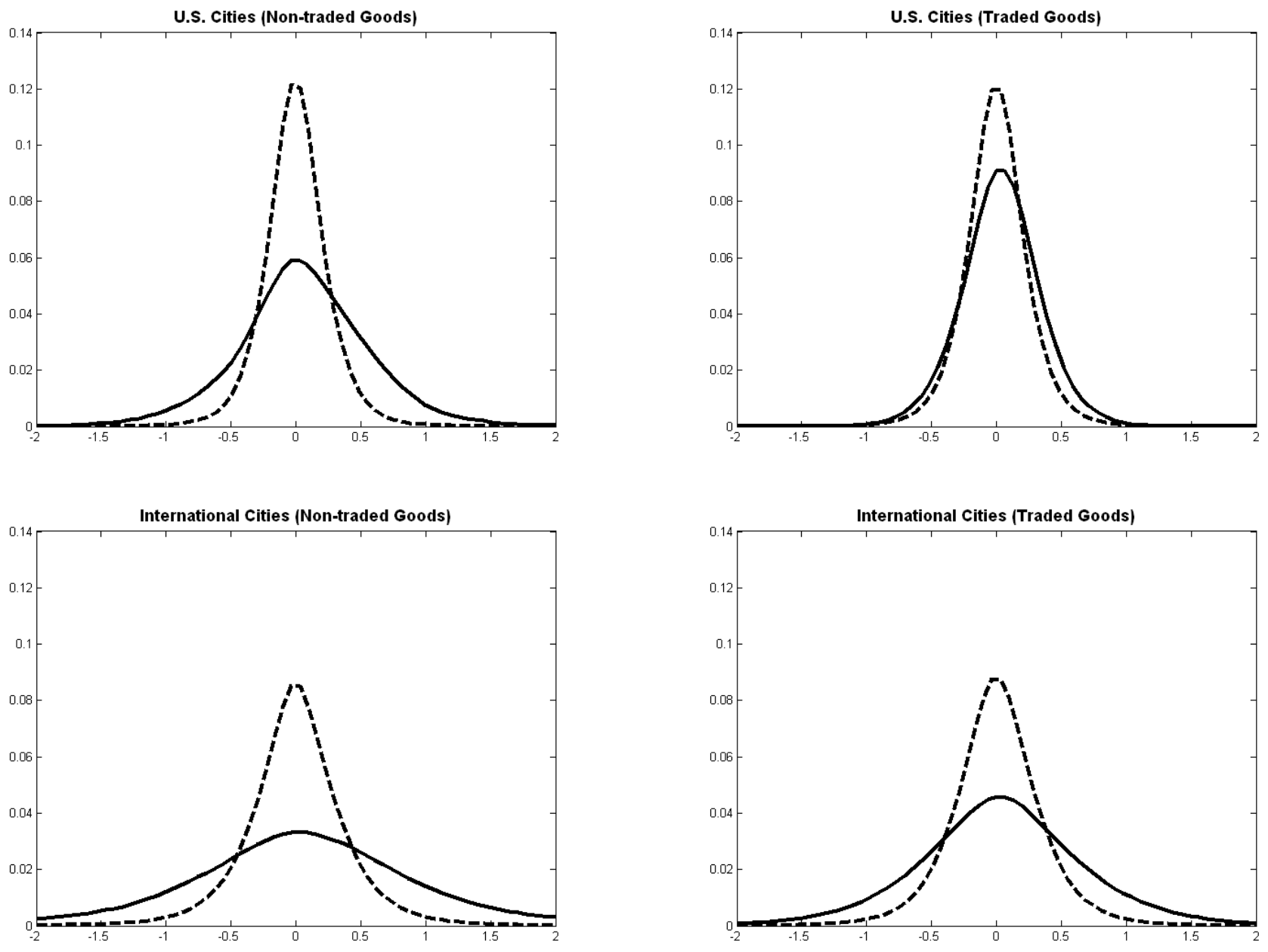

Figure 1. Kernel density estimates of price distributions.

Note: The solid lines are kernel density estimates of the distribution of $q_{i j k}$, time averaged LOP deviations over the period 1990-2005. The dashed lines are kernel density estimates of the distribution of $\left(q_{i j k, t}-q_{i j k}\right)$, time series deviations from these long-run values. Each chart contains a different location and commodity grouping as indicated by the headers. 

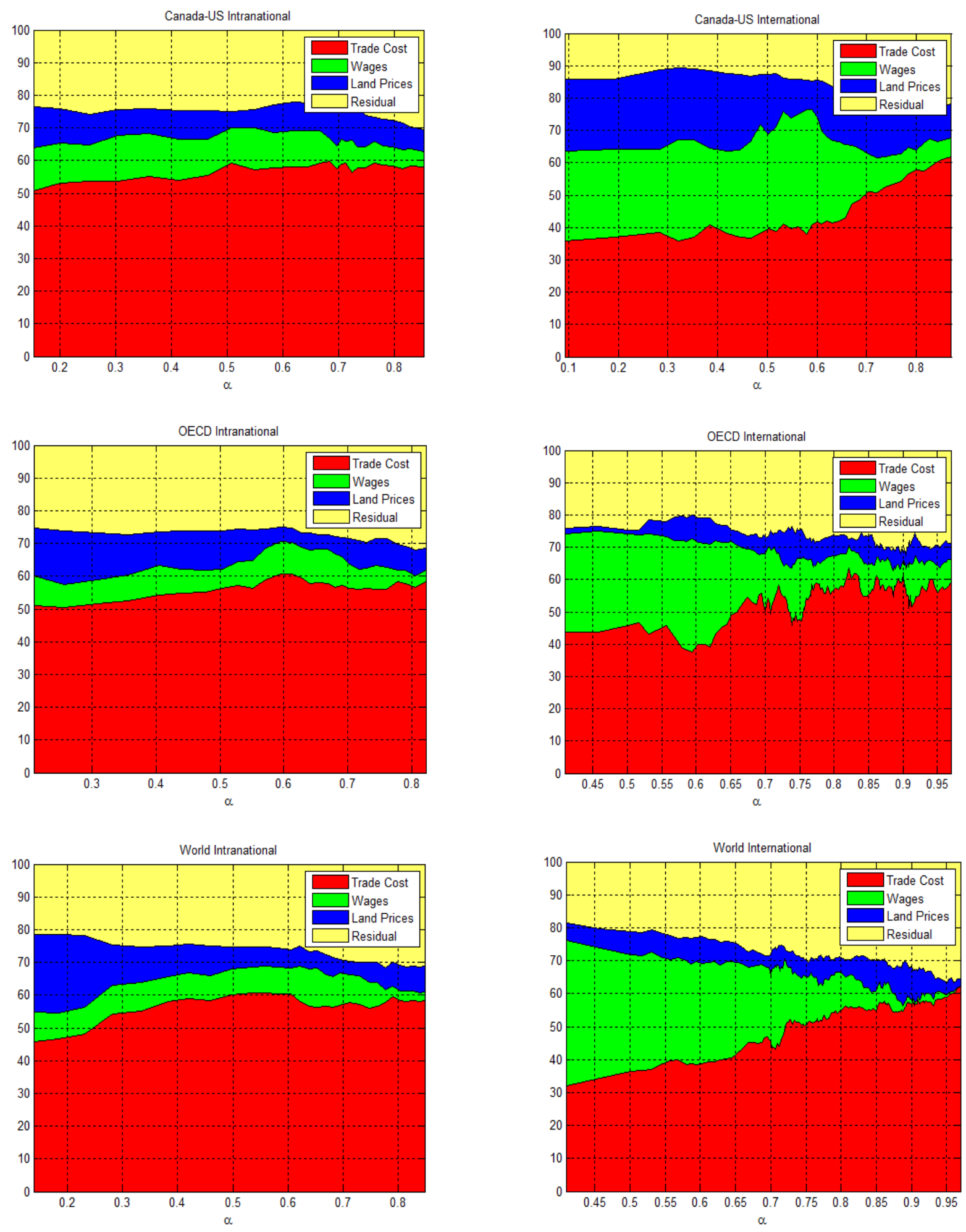

Figure 2. Variance decomposition of price dispersion as a function of $\alpha_{i}$ the share of traded input costs (x-axis) 

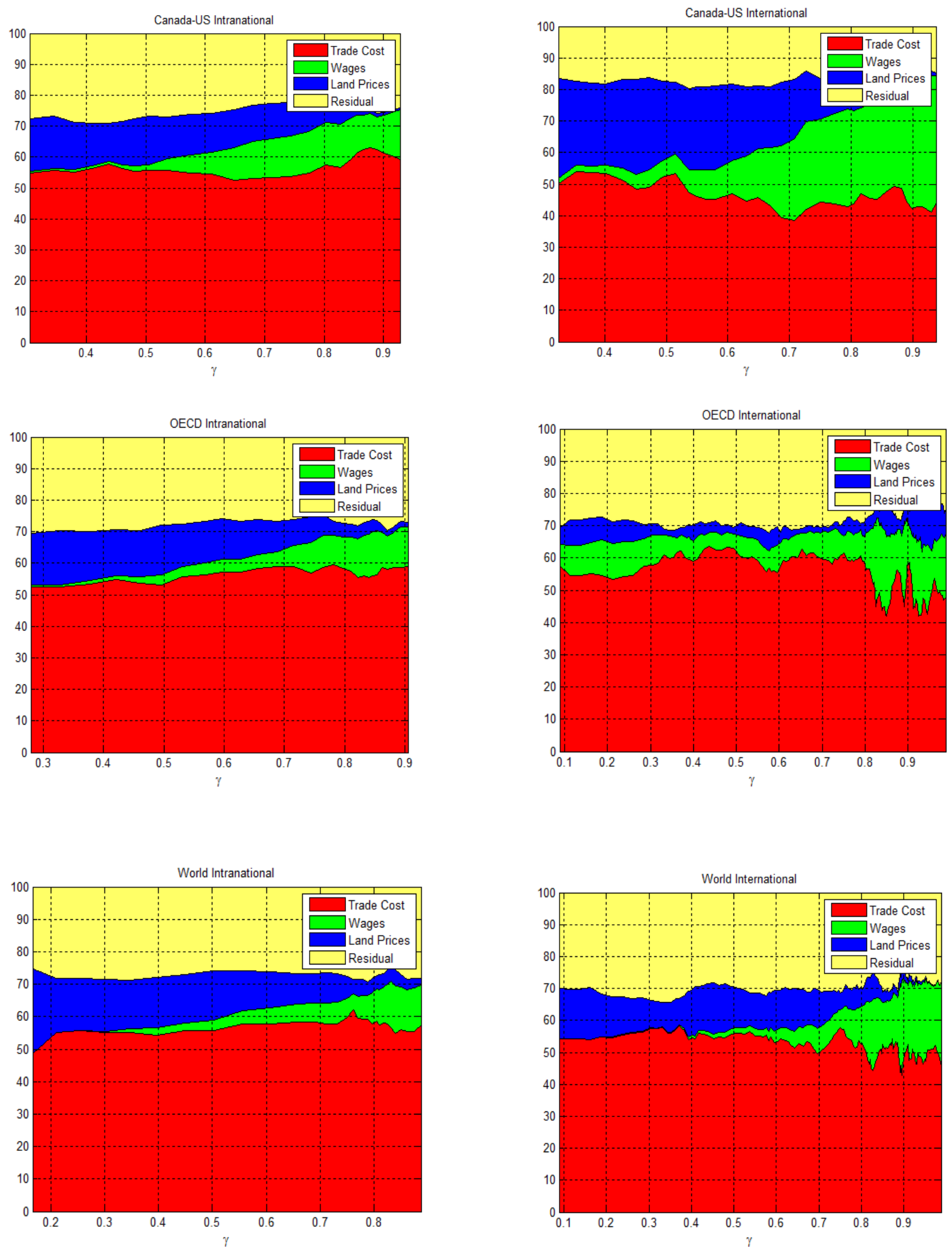

Figure 3. Variance decomposition of price dispersion as a function of $\gamma_{i}$ the labor share of non-traded input costs (x-axis) 


\section{Model Appendix}

This appendix presents the function forms of the model, the first-order conditions and details for the model solution.

\subsection{Function forms}

$$
\begin{aligned}
U\left(C_{j}, N_{j}\right) & \equiv(1-\theta) \log \left(C_{j}\right)+\theta \log L_{j} \\
C_{j} & =\left(\sum_{i}^{M}\left(\beta_{i}\right)^{\frac{1}{\varepsilon}}\left(C_{i j}\right)^{\frac{\varepsilon-1}{\varepsilon}}\right)^{\frac{\varepsilon}{\varepsilon-1}} \\
P_{j} & \equiv\left(\sum_{i} \beta_{i}\left(P_{i j}\right)^{1-\varepsilon}\right)^{\frac{1}{1-\varepsilon}} \\
Y_{j} & =A_{j} N_{j}^{m} \\
R_{i j} & =\left(G_{i j}\right)^{\alpha_{i}}\left(\left(B_{j} N_{i j}^{s}\right)^{\gamma_{i}}\left(K_{i j}\right)^{1-\gamma_{i}}\right)^{1-\alpha_{i}}
\end{aligned}
$$

\subsection{Constraints}

$$
\begin{aligned}
L_{j}+N_{j} & =1 \\
\sum_{i} P_{i j} C_{i j} & =P_{j} C_{j} \\
\sum_{i} P_{i j} C_{i j}^{m} & \leq W_{j}^{m} N_{j}^{m}+\varphi H_{j} K_{j} \\
\sum_{i} P_{i j} C_{i j}^{s} & \leq W_{j}^{s} N_{j}^{s}+(1-\varphi) H_{j} K_{j}
\end{aligned}
$$

where $\varphi \in(0,1)$ is the capital income share received by the manufacturer, $(1-\varphi)$ is the capital income share received by the retailer, $H_{j}$ is the price of capital, and $K_{j}$ is the amount of capital. 
8.3. Consumer and producer problems

$$
\begin{aligned}
& \max _{C_{j}}\left\{(1-\theta) \log \left(C_{j}\right)+\theta \log L_{j}+\lambda_{j}\left[W_{j}^{m}\left(1-L_{j}\right)+\varphi H_{j} K_{j}-P_{j} C_{j}\right]\right\} \\
& \max _{C_{j}}\left\{(1-\theta) \log \left(C_{j}\right)+\theta \log L_{j}+\lambda_{j}\left[W_{j}^{s}\left(1-L_{j}\right)+(1-\varphi) H_{j} K_{j}-P_{j} C_{j}\right]\right\} \\
& \max _{N_{j}^{m}}\left\{Q_{j j} A_{j} N_{j}^{m}-W_{j}^{m} N_{j}^{m}\right\} \\
& \max _{G_{i}, N_{j}^{s}}\left\{P_{i j}\left(G_{i j}\right)^{\alpha_{i}}\left(\left(B_{j} N_{i j}^{s}\right)^{\gamma_{i}}\left(K_{i j}\right)^{1-\gamma_{i}}\right)^{1-\alpha_{i}}-Q_{i j} G_{i j}-W_{j}^{s} N_{i j}^{s}-H_{j} K_{i j}\right\}
\end{aligned}
$$

\subsection{Efficiency conditions}

$$
\begin{aligned}
& C_{i j}^{A}=\beta_{i}\left(\frac{P_{i j}}{P_{j}}\right)^{-\varepsilon} C_{j}^{A} \\
& C_{j}^{A}=\frac{W_{j}^{A}}{P_{j}} \frac{(1-\theta)}{\theta}\left(1-N_{j}^{A}\right) \\
& N_{j}^{m}=1-\theta-\frac{\varphi \theta H_{j} K_{j}}{W_{j}^{m}} \\
& N_{j}^{s}=1-\theta-\frac{(1-\varphi) \theta H_{j} K_{j}}{W_{j}^{s}} \\
& L_{j}^{m}=\theta+\frac{\varphi \theta H_{j} K_{j}}{W_{j}^{m}} \\
& L_{j}^{s}=\theta+\frac{(1-\varphi) \theta H_{j} K_{j}}{W_{j}^{s}} \\
& N_{i j}^{s}=\frac{\left(1-\alpha_{i}\right) \gamma_{i}}{\alpha_{i}} \frac{Q_{i j}}{W_{j}^{s}} R_{i j}\left(\frac{B_{j} Q_{i j}}{W_{j}^{s}} \frac{\left(1-\alpha_{i}\right) \gamma_{i}}{\alpha_{i}}\right)^{\left(\alpha_{i}-1\right) \gamma_{i}}\left(\frac{Q_{i j}}{H_{j}} \frac{\left(1-\alpha_{i}\right)\left(1-\gamma_{i}\right)}{\alpha_{i}}\right)^{\left(\alpha_{i}-1\right)\left(1-\gamma_{i}\right)} \\
& G_{i j}=R_{i j}\left(\frac{B_{j} Q_{i j}}{W_{j}^{s}} \frac{\left(1-\alpha_{i}\right) \gamma_{i}}{\alpha_{i}}\right)^{\left(\alpha_{i}-1\right) \gamma_{i}}\left(\frac{Q_{i j}}{H_{j}} \frac{\left(1-\alpha_{i}\right)\left(1-\gamma_{i}\right)}{\alpha_{i}}\right)^{\left(\alpha_{i}-1\right)\left(1-\gamma_{i}\right)} \\
& K_{i j}=\frac{\left(1-\alpha_{i}\right)\left(1-\gamma_{i}\right)}{\alpha_{i}} \frac{Q_{i j}}{H_{j}} R_{i j}\left(\frac{B_{j} Q_{i j}}{W_{j}^{s}} \frac{\left(1-\alpha_{i}\right) \gamma_{i}}{\alpha_{i}}\right)^{\left(\alpha_{i}-1\right) \gamma_{i}}\left(\frac{Q_{i j}}{H_{j}} \frac{\left(1-\alpha_{i}\right)\left(1-\gamma_{i}\right)}{\alpha_{i}}\right)^{\left(\alpha_{i}-1\right)(1-)} \\
& Q_{j j}=M C_{j}=\frac{W_{j}^{m}}{A_{j}} \\
& P_{i j}=M C_{i j}^{s}=\frac{\left(Q_{i j}\right)^{\alpha_{i}}\left(\left(\frac{W_{j}^{s}}{B_{j}}\right)^{\gamma_{i}}\left(H_{j}\right)^{\left(1-\gamma_{i}\right)}\right)^{\left(1-\alpha_{i}\right)}}{\alpha_{i}^{\alpha_{i}}\left(\left(1-\alpha_{i}\right)\left(\gamma_{i}\right)^{\gamma_{i}}\left(1-\gamma_{i}\right)^{\left(1-\gamma_{i}\right)}\right)^{\left(1-\alpha_{i}\right)}}
\end{aligned}
$$

8.5. Price relationships

$$
Q_{j i}=\left(1+\tau_{j i}\right) Q_{j j}
$$




\subsection{The retail firm}

$$
\left.\begin{array}{c}
N_{j}^{s}=1-\theta-\frac{(1-\varphi) \theta H_{j} K_{j}}{W_{j}^{s}}=\sum_{i} N_{i j}^{s}=\sum_{i}\left\{\begin{array}{c}
\frac{\left(1-\alpha_{i}\right) \gamma_{i}}{\alpha_{i}} \frac{Q_{i j}}{W_{j}^{s}} R_{i j}\left(\frac{B_{j} Q_{i j}}{W_{j}^{s}} \frac{\left(1-\alpha_{i}\right) \gamma_{i}}{\alpha_{i}}\right)^{\left(\alpha_{i}-1\right) \gamma} \\
\times\left(\frac{Q_{i j}}{H_{j}} \frac{\left(1-\alpha_{i}\right)\left(1-\gamma_{i}\right)}{\alpha_{i}}\right)^{\left(\alpha_{i}-1\right)\left(1-\gamma_{i}\right)}
\end{array}\right\} \\
G_{i j}=R_{i j}\left(\frac{B_{j} Q_{i j}}{W_{j}^{s}} \frac{\left(1-\alpha_{i}\right) \gamma_{i}}{\alpha_{i}}\right)^{\left(\alpha_{i}-1\right) \gamma_{i}}\left(\frac{Q_{i j}}{H_{j}} \frac{\left(1-\alpha_{i}\right)\left(1-\gamma_{i}\right)}{\alpha_{i}}\right)^{\left(\alpha_{i}-1\right)\left(1-\gamma_{i}\right)}
\end{array}\right\}
$$

\subsection{General equilibrium}

\subsubsection{Manufacturing Labor Market}

The labor supply of the manufacturer is used in the manufacturing process, which implies:

$$
\frac{Y_{j}}{A_{j}}=1-\theta-\frac{\varphi \theta H_{j} K_{j}}{W_{j}^{m}}
$$

\subsubsection{Goods Market}

In the global general equilibrium all the conditions of partial equilibrium must hold. However we also require that the supply of each good equals the demand for each good. This is where the treatment of trade costs becomes crucial. We will assume that trade costs are of the iceberg variety, so the physical resource constraint for good $j$ must satisfy:

$$
Y_{j}=\sum_{i} G_{j i}\left(1+\tau_{i j}\right)
$$

In words: the units produced equal the demand of traded inputs of retailers at the destinations plus a fraction lost to iceberg costs. The loss along any bilateral trade route is proportional to the volume of trade along that branch:

$$
\frac{T_{j}}{Y_{j}}=\frac{\sum_{i} G_{j i} \tau_{i j}}{\sum_{i} G_{j i}\left(1+\tau_{i j}\right)}
$$

Substituting the optimal traded input choices of the retailers into the resource constraint we arrive at:

$$
Y_{j}=\sum_{i} R_{j i}\left(\frac{B_{i} Q_{j i}}{W_{i}^{s}} \frac{\left(1-\alpha_{j}\right) \gamma_{j}}{\alpha_{j}}\right)^{\left(\alpha_{j}-1\right) \gamma_{j}}\left(\frac{Q_{j i}}{H_{i}} \frac{\left(1-\alpha_{j}\right)\left(1-\gamma_{j}\right)}{\alpha_{j}}\right)^{\left(\alpha_{j}-1\right)\left(1-\gamma_{j}\right)}\left(1+\tau_{j i}\right)
$$

Recall 8.23:

$$
\frac{Y_{j}}{A_{j}}=1-\theta-\frac{\varphi \theta H_{j} K_{j}}{W_{j}^{m}}
$$


Combining these last two we get:

$$
\begin{aligned}
& \sum_{i} R_{j i}\left(\frac{B_{i} Q_{j i}}{W_{i}^{s}} \frac{\left(1-\alpha_{j}\right) \gamma_{j}}{\alpha_{j}}\right)^{\left(\alpha_{j}-1\right) \gamma_{j}}\left(\frac{Q_{j i}}{H_{i}} \frac{\left(1-\alpha_{j}\right)\left(1-\gamma_{j}\right)}{\alpha_{j}}\right)^{\left(\alpha_{j}-1\right)\left(1-\gamma_{j}\right)} \\
= & A_{j}\left(1-\theta-\frac{\varphi \theta H_{j} K_{j}}{W_{j}^{m}}\right)
\end{aligned}
$$

The equilibrium of the retailer implies:

$$
R_{i j}=C_{i j}^{m}+C_{i j}^{s}=\beta_{i}\left(\frac{P_{i j}}{P_{j}}\right)^{-\varepsilon}\left(C_{j}^{m}+C_{j}^{s}\right)
$$

Assuming that $\varepsilon=1$ (for the rest of the text), we have:

$$
\begin{gathered}
R_{i j}=C_{i j}^{m}+C_{i j}^{s}=\frac{\beta_{i}}{P_{i j}}\left(P_{j} C_{j}^{m}+P_{j} C_{j}^{s}\right)=\frac{\beta_{i}}{P_{i j}}\left(N_{j}^{m} W_{j}^{m}+N_{j}^{s} W_{j}^{s}+H_{j} K_{j}\right) \\
R_{j i}=\frac{\beta_{j}}{P_{j i}}\left(N_{i}^{m} W_{i}^{m}+N_{i}^{s} W_{i}^{s}+H_{i} K_{i}\right)
\end{gathered}
$$

In words: total income/retail sales of good $i$ is equal to the share of that good in the budget of the region. Thus, we have

$$
\begin{aligned}
& \sum_{i} R_{j i}\left(\frac{B_{i} Q_{j i}}{W_{i}^{s}} \frac{\left(1-\alpha_{j}\right) \gamma_{j}}{\alpha_{j}}\right)^{\left(\alpha_{j}-1\right) \gamma_{j}}\left(\frac{Q_{j i}}{H_{i}} \frac{\left(1-\alpha_{j}\right)\left(1-\gamma_{j}\right)}{\alpha_{j}}\right)^{\left(\alpha_{j}-1\right)\left(1-\gamma_{j}\right)}\left(1+\tau_{j i}\right) \\
&= A_{j}\left(1-\theta-\frac{\varphi \theta H_{j} K_{j}}{W_{j}^{m}}\right) \\
& \sum_{i}\left\{\begin{array}{c}
\frac{\beta_{j}}{P_{j i}}\left(N_{i}^{m} W_{i}^{m}+N_{i}^{s} W_{i}^{s}+H_{i} K_{i}\right)\left(\frac{B_{i} Q_{j i}}{W_{i}^{s}} \frac{\left(1-\alpha_{j}\right) \gamma_{j}}{\alpha_{j}}\right)^{\left(\alpha_{j}-1\right) \gamma_{j}} \\
\times\left(\frac{Q_{j i}}{H_{i}} \frac{\left(1-\alpha_{j}\right)\left(1-\gamma_{j}\right)}{\alpha_{j}}\right)^{\left(\alpha_{j}-1\right)\left(1-\gamma_{j}\right)}\left(1+\tau_{j i}\right)
\end{array}\right\}=A_{j}\left(1-\theta-\frac{\varphi \theta H_{j} K_{j}}{W_{j}^{m}}\right)
\end{aligned}
$$

Recall the price set by the retailer:

$$
P_{i j}=\frac{\left(Q_{i j}\right)^{\alpha_{i}}\left(\left(\frac{W_{j}^{s}}{B_{j}}\right)^{\gamma_{i}}\left(H_{j}\right)^{\left(1-\gamma_{i}\right)}\right)^{\left(1-\alpha_{i}\right)}}{\alpha_{i}^{\alpha_{i}}\left(\left(1-\alpha_{i}\right)\left(\gamma_{i}\right)^{\gamma_{i}}\left(1-\gamma_{i}\right)^{\left(1-\gamma_{i}\right)}\right)^{\left(1-\alpha_{i}\right)}}
$$

which is to say:

$$
P_{j i}=\frac{\left(Q_{j i}\right)^{\alpha_{j}}\left(\frac{W_{i}^{s}}{B_{i}}\right)^{\left(1-\alpha_{j}\right) \gamma_{j}}\left(H_{i}\right)^{\left(1-\alpha_{j}\right)\left(1-\gamma_{j}\right)}}{\alpha_{j}^{\alpha_{j}}\left(\left(1-\alpha_{j}\right) \gamma_{j}\right)^{\left(1-\alpha_{j}\right) \gamma_{j}}\left(\left(1-\alpha_{j}\right)\left(1-\gamma_{j}\right)\right)^{\left(1-\alpha_{j}\right)\left(1-\gamma_{j}\right)}}
$$


Thus,

$$
\begin{aligned}
\sum_{i}\left\{\begin{array}{c}
\frac{\beta_{j}}{\frac{\left(Q_{j i}\right)^{\alpha_{j}}\left(\frac{W_{i}^{s}}{B_{i}}\right){ }^{\left(1-\alpha_{j}\right) \gamma_{j}}\left(H_{i}\right)\left(1-\alpha_{j}\right)\left(1-\gamma_{j}\right)}{\alpha_{j}^{\alpha_{j}}\left(\left(1-\alpha_{j}\right) \gamma_{j}\right)}\left(N^{\left(1-\alpha_{j}\right) \gamma_{j}}\left(\left(1-\alpha_{j}\right)\left(1-\gamma_{j}\right)\right)^{\left(1-\alpha_{j}\right)\left(1-\gamma_{j}\right)}\right.}\left(W_{i}^{m}+N_{i}^{s} W_{i}^{s}+H_{i} K_{i}\right) \\
\times\left(\frac{B_{i} Q_{j i}}{W_{i}^{s}} \frac{\left(1-\alpha_{j}\right) \gamma_{j}}{\alpha_{j}}\right)^{\left(\alpha_{j}-1\right) \gamma_{j}}\left(\frac{Q_{j i}}{H_{i}} \frac{\left(1-\alpha_{j}\right)\left(1-\gamma_{j}\right)}{\alpha_{j}}\right)^{\left(\alpha_{j}-1\right)\left(1-\gamma_{j}\right)}\left(1+\tau_{j i}\right)
\end{array}\right\} \\
=A_{j}\left(1-\theta-\frac{\varphi \theta H_{j} K_{j}}{W_{j}^{m}}\right) \\
\quad \sum_{i} \frac{\beta_{j}}{Q_{j i}}\left(N_{i}^{m} W_{i}^{m}+N_{i}^{s} W_{i}^{s}+H_{i} K_{i}\right) \alpha_{j}\left(1+\tau_{j i}\right)=A_{j}\left(1-\theta-\frac{\varphi \theta H_{j} K_{j}}{W_{j}^{m}}\right)
\end{aligned}
$$

By using $Q_{j j}=\frac{W_{j}^{m}}{A_{j}}$ and $Q_{j i}=\left(1+\tau_{j i}\right) Q_{j j}$, we can write

$$
\begin{gathered}
\sum_{i} \frac{\beta_{j}}{\left(1+\tau_{j i}\right) W_{j}^{m}}\left(N_{i}^{m} W_{i}^{m}+N_{i}^{s} W_{i}^{s}+H_{i} K_{i}\right) \alpha_{j}\left(1+\tau_{j i}\right)=\left(1-\theta-\frac{\varphi \theta H_{j} K_{j}}{W_{j}^{m}}\right) \\
\alpha_{j} \beta_{j} \sum_{i}\left(N_{i}^{m} W_{i}^{m}+N_{i}^{s} W_{i}^{s}+H_{i} K_{i}\right)=W_{j}^{m}\left(1-\theta-\frac{\varphi \theta H_{j} K_{j}}{W_{j}^{m}}\right) \\
\alpha_{j} \beta_{j} \sum_{i}\left(N_{i}^{m} W_{i}^{m}+N_{i}^{s} W_{i}^{s}+H_{i} K_{i}\right)=W_{j}^{m} N_{j}^{m}
\end{gathered}
$$

This is the first equation for the relation between $N^{m} W^{m}, N^{s} W^{s}$, and $H K$.

\subsubsection{Retailing Labor Market}

We have the following condition for the retailing labor market equilibrium:

$$
\begin{aligned}
& N_{j}^{s}=\sum_{i} N_{i j}^{s}=\sum_{i}\left\{\begin{array}{c}
\frac{\left(1-\alpha_{i}\right) \gamma_{i}}{\alpha_{i}} \frac{Q_{i j}}{W_{j}^{s}} R_{i j}\left(\frac{B_{j} Q_{i j}}{W_{j}^{s}} \frac{\left(1-\alpha_{i}\right) \gamma_{i}}{\alpha_{i}}\right)^{\left(\alpha_{i}-1\right) \gamma} \\
\times\left(\frac{Q_{i j}}{H_{j}} \frac{\left(1-\alpha_{i}\right)\left(1-\gamma_{i}\right)}{\alpha_{i}}\right)^{\left(\alpha_{i}-1\right)\left(1-\gamma_{i}\right)}
\end{array}\right\}
\end{aligned}
$$

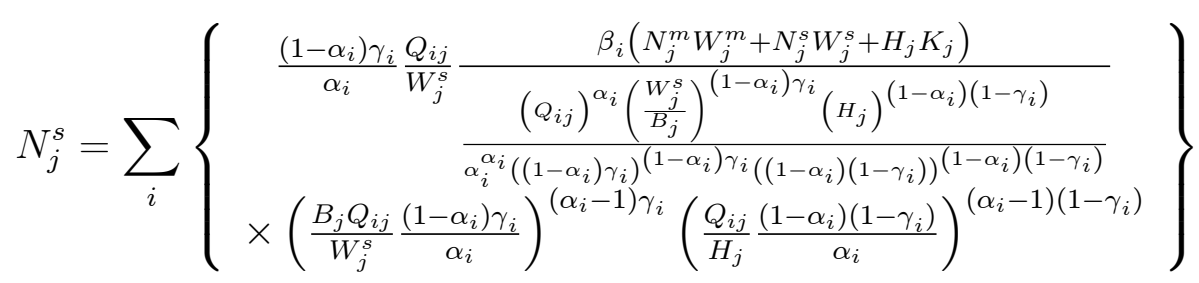

$$
\begin{aligned}
& N_{j}^{s} W_{j}^{s}=\left(N_{j}^{m} W_{j}^{m}+N_{j}^{s} W_{j}^{s}+H_{j} K_{j}\right) \sum_{i}\left(1-\alpha_{i}\right) \gamma_{i} \beta_{i}
\end{aligned}
$$

This is the second equation for the relation between $N^{m} W^{m}, N^{s} W^{s}$, and $H K$. 


\subsubsection{Capital Market}

We have the following condition for the capital market equilibrium:

$$
\begin{gathered}
K_{j}=\sum_{i} K_{i j}=\sum_{i}\left\{\begin{array}{c}
\frac{\left(1-\alpha_{i}\right)\left(1-\gamma_{i}\right)}{\alpha_{i}} \frac{Q_{i j}}{H_{j}} R_{i j}\left(\frac{B_{j} Q_{i j}}{W_{j}^{s}} \frac{\left(1-\alpha_{i}\right) \gamma_{i}}{\alpha_{i}}\right)^{\left(\alpha_{i}-1\right) \gamma} \\
\times\left(\frac{Q_{i j}}{H_{j}} \frac{\left(1-\alpha_{i}\right)\left(1-\gamma_{i}\right)}{\alpha_{i}}\right)^{\left(\alpha_{i}-1\right)\left(1-\gamma_{i}\right)}
\end{array}\right\} \\
H_{j} K_{j}=\left(N_{j}^{m} W_{j}^{m}+N_{j}^{s} W_{j}^{s}+H_{j} K_{j}\right) \sum_{i}\left(1-\alpha_{i}\right)\left(1-\gamma_{i}\right) \beta_{i}
\end{gathered}
$$

This is the third equation for the relation between $N^{m} W^{m}, N^{s} W^{s}$, and $H K$.

\subsubsection{Implications for Wages, Rents, Wage Income, and Capital Income}

Recall 8.28, 8.29, 8.30, which are:

$$
\begin{gathered}
N_{j}^{m} W_{j}^{m}=\alpha_{j} \beta_{j} \sum_{i}\left(N_{i}^{m} W_{i}^{m}+N_{i}^{s} W_{i}^{s}+H_{i} K_{i}\right) \\
N_{j}^{s} W_{j}^{s}=\left(N_{j}^{m} W_{j}^{m}+N_{j}^{s} W_{j}^{s}+H_{j} K_{j}\right) \sum_{i}\left(1-\alpha_{i}\right) \gamma_{i} \beta_{i} \\
H_{j} K_{j}=\left(N_{j}^{m} W_{j}^{m}+N_{j}^{s} W_{j}^{s}+H_{j} K_{j}\right) \sum_{i}\left(1-\alpha_{i}\right)\left(1-\gamma_{i}\right) \beta_{i}
\end{gathered}
$$

Combine 8.29 and 8.30 to get:

$$
\frac{H_{j} K_{j}}{N_{j}^{s} W_{j}^{s}}=\frac{\sum_{i}\left(1-\alpha_{i}\right)\left(1-\gamma_{i}\right) \beta_{i}}{\sum_{i}\left(1-\alpha_{i}\right) \gamma_{i} \beta_{i}}
$$

and

$$
\left(H_{j} K_{j}+N_{j}^{s} W_{j}^{s}\right)=N_{j}^{m} W_{j}^{m} \frac{\sum_{i}\left(1-\alpha_{i}\right) \beta_{i}}{\left(1-\sum_{i}\left(1-\alpha_{i}\right) \beta_{i}\right)}
$$

and thus

$$
\frac{N_{j}^{s} W_{j}^{s}}{N_{j}^{m} W_{j}^{m}}=\frac{\sum_{i}\left(1-\alpha_{i}\right) \gamma_{i} \beta_{i}}{\left(1-\sum_{i}\left(1-\alpha_{i}\right) \beta_{i}\right)}
$$

which show that the sectoral wage incomes and capital incomes are all proportional to each other within each city.

Recall the individual optimality condition for the retailer:

$$
\begin{gathered}
N_{j}^{s}=1-\theta-\frac{(1-\varphi) \theta H_{j} K_{j}}{W_{j}^{s}} \\
N_{j}^{s} W_{j}^{s}=W_{j}^{s}(1-\theta)-(1-\varphi) \theta H_{j} K_{j}
\end{gathered}
$$


Combine this with 8.31 to get:

$$
\begin{gathered}
H_{j} K_{j}=\frac{\left(N_{j}^{s} W_{j}^{s}\right) \sum_{i}\left(1-\alpha_{i}\right)\left(1-\gamma_{i}\right) \beta_{i}}{\sum_{i}\left(1-\alpha_{i}\right) \gamma_{i} \beta_{i}} \\
N_{j}^{s} W_{j}^{s}\left(1+\frac{(1-\varphi) \theta \sum_{i}\left(1-\alpha_{i}\right)\left(1-\gamma_{i}\right) \beta_{i}}{\sum_{i}\left(1-\alpha_{i}\right) \gamma_{i} \beta_{i}}\right)=W_{j}^{s}(1-\theta) \\
N_{j}^{s}=\frac{(1-\theta) \sum_{i}\left(1-\alpha_{i}\right) \gamma_{i} \beta_{i}}{\left(\sum_{i}\left(1-\alpha_{i}\right) \gamma_{i} \beta_{i}\right)+(1-\varphi) \theta\left(\sum_{i}\left(1-\alpha_{i}\right)\left(1-\gamma_{i}\right) \beta_{i}\right)}
\end{gathered}
$$

which shows that $N_{j}^{s}$ is constant across regions. In a special case in which the share of capital is equal to zero in the retail production function (i.e., $\gamma_{i}=0$ ), or in which the share of capital income received by the retailer is equal to zero (i.e., $\varphi=1$ ), we have $N_{j}^{s}=(1-\theta)$.

Combine 8.33 with 8.28 to get:

$$
\frac{\frac{N_{j}^{s} W_{j}^{s}\left(1-\sum_{i}\left(1-\alpha_{i}\right) \beta_{i}\right)}{\sum_{i}\left(1-\alpha_{i}\right) \gamma_{i} \beta_{i}}}{\frac{N_{k}^{s} W_{k}^{s}\left(1-\sum_{i}\left(1-\alpha_{i}\right) \beta_{i}\right)}{\sum_{i}\left(1-\alpha_{i}\right) \gamma_{i} \beta_{i}}}=\frac{N_{j}^{m} W_{j}^{m}}{N_{k}^{m} W_{k}^{m}}=\frac{\alpha_{j} \beta_{j}}{\alpha_{k} \beta_{k}}=\frac{N_{j}^{s} W_{j}^{s}}{N_{k}^{s} W_{k}^{s}}
$$

which show that the manufacturing wage income and the retailing wage income are proportional across cities. It is implied that:

$$
\frac{W_{j}^{s}}{W_{k}^{s}}=\frac{\alpha_{j} \beta_{j}}{\alpha_{k} \beta_{k}}
$$

since $N_{j}^{s}$ is constant across regions. If we also use 8.31, we obtain:

$$
\frac{H_{j} K_{j}}{H_{k} K_{k}}=\frac{\alpha_{j} \beta_{j}}{\alpha_{k} \beta_{k}}
$$

where $K_{A}$ is the capital stock in city $A=j, k$.

Recall the individual optimality conditions for both the retailer and the manufacturer:

$$
\begin{aligned}
W_{j}^{m} N_{j}^{m} & =W_{j}^{m}(1-\theta)-\varphi \theta H_{j} K_{j} \\
W_{j}^{s} N_{j}^{s} & =W_{j}^{s}(1-\theta)-(1-\varphi) \theta H_{j} K_{j}
\end{aligned}
$$

These conditions can be combined to obtain:

$$
\frac{W_{j}^{m}}{W_{j}^{s}}=\frac{\varphi(1-\theta)-\varphi N_{j}^{s}}{(1-\varphi)(1-\theta)-(1-\varphi) N_{j}^{m}}
$$


Recall 8.33:

$$
\frac{N_{j}^{m} W_{j}^{m}}{N_{j}^{s} W_{j}^{s}}=\frac{\left(1-\sum_{i}\left(1-\alpha_{i}\right) \beta_{i}\right)}{\sum_{i}\left(1-\alpha_{i}\right) \gamma_{i} \beta_{i}}
$$

Combine the last two expressions to get:

$$
\begin{aligned}
& \frac{N_{j}^{m} W_{j}^{m}}{N_{j}^{s} W_{j}^{s}}=\frac{N_{j}^{m}}{N_{j}^{s}} \frac{\varphi(1-\theta)-\varphi N_{j}^{s}}{(1-\varphi)(1-\theta)-(1-\varphi) N_{j}^{m}}=\frac{\left(1-\sum_{i}\left(1-\alpha_{i}\right) \beta_{i}\right)}{\sum_{i}\left(1-\alpha_{i}\right) \gamma_{i} \beta_{i}} \\
& N_{j}^{m}\left(\frac{\varphi(1-\theta)}{N_{j}^{s}}-\varphi\right) \sum_{i}\left(1-\alpha_{i}\right) \gamma_{i} \beta_{i} \\
= & (1-\varphi)(1-\theta)\left(1-\sum_{i}\left(1-\alpha_{i}\right) \beta_{i}\right)-(1-\varphi) N_{j}^{m}\left(1-\sum_{i}\left(1-\alpha_{i}\right) \beta_{i}\right)
\end{aligned}
$$

which can be combined with 8.34 (i.e., $N_{j}^{s}$ ) to obtain:

$$
\begin{aligned}
N_{j}^{m} & =(1-\theta)-\frac{\varphi \theta\left(\phi_{0}-\phi_{1}\right)(1-\theta)}{\varphi \theta\left(\phi_{0}-\phi_{1}\right)+\left(1-\phi_{0}\right)} \\
& =(1-\theta) \text { when } \varphi=0 \text { or } \gamma_{i}=1
\end{aligned}
$$

where $\phi_{0} \equiv \sum_{i}\left(1-\alpha_{i}\right) \beta_{i}, \phi_{1} \equiv \sum_{i}\left(1-\alpha_{i}\right) \gamma_{i} \beta_{i}, \phi_{0}-\phi_{1}=\sum_{i}\left(1-\alpha_{i}\right)\left(1-\gamma_{i}\right) \beta_{i} \cdot \phi_{2} \equiv$ $\sum_{i} \alpha_{i} \beta_{i}=1-\phi_{0}$. This shows that $N_{j}^{m}$ is constant and equal across cities. The level of effort is equals, $(1-\theta)$ when either rental income is zero for the manufacturer $(\varphi=0)$ or when retail production is labor-only $\gamma_{i}=1$. Effort is declining in asset income.

$$
\begin{aligned}
\frac{N_{j}^{m}}{(1-\theta)} & =1-\frac{\varphi \theta\left(\phi_{0}-\phi_{1}\right)}{\varphi \theta\left(\phi_{0}-\phi_{1}\right)+\left(1-\phi_{0}\right)} \\
\frac{\partial \frac{N_{j}^{m}}{(1-\theta)}}{\partial \varphi} & =-\theta\left(\phi_{0}-\phi_{1}\right) d^{-1}+\varphi \theta\left(\phi_{0}-\phi_{1}\right) d^{-2} \\
& =\theta\left(\phi_{0}-\phi_{1}\right) d^{-1}\left[-1+\varphi d^{-1}\right] \\
\operatorname{sign} \frac{\partial \frac{N_{j}^{m}}{\partial \varphi-\theta)}}{\partial \varphi} & =\operatorname{sign}\left[-1+\varphi d^{-1}\right] \text { since } \theta\left(\phi_{0}-\phi_{1}\right) d^{-1}>0 \\
\varphi & <d \\
N_{j}^{m}=\frac{\left(1-\phi_{0}\right)(1-\theta)}{\left(1-\phi_{0}\right)+\varphi \theta\left(\phi_{0}-\phi_{1}\right)} & \\
N_{j}^{s}=\frac{\phi_{1}(1-\theta)}{\phi_{1}+(1-\varphi) \theta\left(\phi_{0}-\phi_{1}\right)} & (1-\varphi) \theta\left(\phi_{0}-\phi_{1}\right) \\
\frac{\left(1-\phi_{0}\right)+\varphi \theta\left(\phi_{0}-\phi_{1}\right)}{W_{j}^{m}} &
\end{aligned}
$$




\subsection{Implications for Price Ratios across Cities}

Recall the retail price of good $i$ in city $j$ and city $k$ :

$$
\begin{aligned}
& P_{i j}=\frac{\left(Q_{i j}\right)^{\alpha_{i}}\left(\frac{W_{j}^{s}}{B_{j}}\right)^{\left(1-\alpha_{i}\right) \gamma_{i}}\left(H_{j}\right)^{\left(1-\alpha_{i}\right)\left(1-\gamma_{i}\right)}}{\alpha_{i}^{\alpha_{i}}\left(\left(1-\alpha_{i}\right) \gamma_{i}\right)^{\left(1-\alpha_{i}\right) \gamma_{i}}\left(\left(1-\alpha_{i}\right)\left(1-\gamma_{i}\right)\right)^{\left(1-\alpha_{i}\right)\left(1-\gamma_{i}\right)}} \\
& P_{i k}=\frac{\left(Q_{i k}\right)^{\alpha_{i}}\left(\frac{W_{k}^{s}}{B_{k}}\right)^{\left(1-\alpha_{i}\right) \gamma_{i}}\left(H_{k}\right)^{\left(1-\alpha_{i}\right)\left(1-\gamma_{i}\right)}}{\alpha_{i}^{\alpha_{i}}\left(\left(1-\alpha_{i}\right) \gamma_{i}\right)^{\left(1-\alpha_{i}\right) \gamma_{i}}\left(\left(1-\alpha_{i}\right)\left(1-\gamma_{i}\right)\right)^{\left(1-\alpha_{i}\right)\left(1-\gamma_{i}\right)}}
\end{aligned}
$$

Take their ratio to get:

$$
\frac{P_{i j}}{P_{i k}}=\frac{\left(Q_{i j}\right)^{\alpha_{i}}\left(\frac{W_{j}^{s}}{B_{j}}\right)^{\left(1-\alpha_{i}\right) \gamma_{i}}\left(H_{j}\right)^{\left(1-\alpha_{i}\right)\left(1-\gamma_{i}\right)}}{\left(Q_{i k}\right)^{\alpha_{i}}\left(\frac{W_{k}^{s}}{B_{k}}\right)^{\left(1-\alpha_{i}\right) \gamma_{i}}\left(H_{k}\right)^{\left(1-\alpha_{i}\right)\left(1-\gamma_{i}\right)}}
$$

By using $Q_{i j}=\left(1+\tau_{i j}\right) Q_{i i}$, we can write the ratio of the price of good $i$ across regions $j$ and $k$ as follows:

$$
\frac{P_{i j}}{P_{i k}}=\frac{\left(\left(1+\tau_{i j}\right)\right)^{\alpha_{i}}}{\left(\left(1+\tau_{i k}\right)\right)^{\alpha_{i}}} \frac{\left(\frac{W_{j}^{s}}{B_{j}}\right)^{\left(1-\alpha_{i}\right) \gamma_{i}}\left(H_{j}\right)^{\left(1-\alpha_{i}\right)\left(1-\gamma_{i}\right)}}{\left(\frac{W_{k}^{s}}{B_{k}}\right)^{\left(1-\alpha_{i}\right) \gamma_{i}}\left(H_{k}\right)^{\left(1-\alpha_{i}\right)\left(1-\gamma_{i}\right)}}
$$

By using 8.35 and 8.36, the analytical solution for the price ratios can be written as:

$$
\frac{P_{i j}}{P_{i k}}=\left(\left(\frac{B_{k}}{B_{j}}\right)^{\gamma_{i}} \frac{\alpha_{j} \beta_{j}}{\alpha_{k} \beta_{k}}\right)^{\left(1-\alpha_{i}\right)}\left(\frac{1+\tau_{i j}}{1+\tau_{i k}}\right)^{\alpha_{i}}\left(\frac{K_{k}}{K_{j}}\right)^{\left(1-\alpha_{i}\right)\left(1-\gamma_{i}\right)}
$$

where $K_{j}$ is the total amount of capital in city $j$.

\section{Estimation Appendix}

The derivation of the variance decomposition of equation 5.5 can be written as follows:

$$
\begin{aligned}
\operatorname{var}_{j k}\left[E_{t}\left(q_{i j k, t}\right)\right]= & \operatorname{var}_{j k}\left[\left(1-\widehat{\alpha}_{i}\right) \widehat{\gamma}_{i} E_{t}\left(\omega_{j k, t}\right)\right]+\operatorname{var}_{j k}\left[\left(1-\widehat{\alpha}_{i}\right)\left(1-\widehat{\gamma}_{i}\right) E_{t}\left(h_{j k, t}\right)\right] \\
& +\operatorname{var}_{j k}\left[\widehat{\alpha}_{i} E_{t}\left(\widehat{\mathbf{I}}_{i j k, t} \widehat{\delta}_{i} d_{j k}\right)\right]+\operatorname{var}_{j k}\left[E_{t}\left(\widehat{\varepsilon}_{i j k, t}\right)\right] \\
& +2 \operatorname{cov}\left(\left(1-\widehat{\alpha}_{i}\right) \widehat{\gamma}_{i} E_{t}\left(\omega_{j k, t}\right),\left(1-\widehat{\alpha}_{i}\right)\left(1-\widehat{\gamma}_{i}\right) E_{t}\left(h_{j k, t}\right)\right) \\
& +2 \operatorname{cov}\left(\left(1-\widehat{\alpha}_{i}\right) \widehat{\gamma}_{i} E_{t}\left(\omega_{j k, t}\right), \widehat{\alpha}_{i} E_{t}\left(\widehat{\mathbf{I}}_{i j k, t} \widehat{\delta}_{i} d_{j k}\right)\right) \\
& +2 \operatorname{cov}\left(\left(1-\widehat{\alpha}_{i}\right)\left(1-\widehat{\gamma}_{i}\right) E_{t}\left(h_{j k, t}\right), \widehat{\alpha}_{i} E_{t}\left(\widehat{\mathbf{I}}_{i j k, t} \widehat{\delta}_{i} d_{j k}\right)\right)
\end{aligned}
$$

where $\widehat{\alpha}_{i}$ 's, $\widehat{\gamma}_{i}$ 's, $\widehat{\mathbf{I}}_{i j k}$ 's, $\widehat{\delta}_{i}$ 's and $\widehat{\varepsilon}_{i j k}$ 's are all estimated values for the relevant variables. Note that the covariance terms including $E_{t}\left(\widehat{\varepsilon}_{i j k, t}\right)$ are equal to zero by OLS regression. 